\title{
Secreted Frizzled Related Proteins in Cardiovascular and Metabolic Diseases
}

\section{OPEN ACCESS}

Edited by:

Jean-François Tanti,

U1065 Centre Méditerranéen de Médecine Moléculaire (INSERM),

France

Reviewed by:

Juergen Eckel,

German Diabetes Center (DDZ),

Germany

Azhar Rasul,

Government College University,

Pakistan

*Correspondence:

Lixian Xu

xIx1863@163.com

Xingchun Gou

gouxingchun@189.cn

${ }^{\dagger}$ These authors have contributed equally to this work

Specialty section:

This article was submitted to Diabetes: Molecular Mechanisms,

a section of the journal

Frontiers in Endocrinology

Received: 20 May 2021

Accepted: 23 July 2021

Published: 20 August 2021

Citation:

Guan H, Zhang J, Luan J, Xu H, Huang Z, Yu Q, Gou X and Xu L

(2021) Secreted Frizzled Related

Proteins in Cardiovascular

and Metabolic Diseases.

Front. Endocrinol. 12:712217. doi: 10.3389/fendo.2021.712217

\author{
Hua Guan ${ }^{1,2+}$, Jin Zhang ${ }^{3 \dagger}$, Jing Luan ${ }^{1,4 \dagger}$, Hao Xu ${ }^{5}$, Zhenghao Huang ${ }^{2}$, Qi Y $u^{2}$, \\ Xingchun Gou ${ }^{4 *}$ and Lixian $\mathrm{Xu}^{1 *}$
}

1 State Key Laboratory of Military Stomatology \& National Clinical Research Center for Oral Diseases \& Shaanxi Engineering Research Center for Dental Materials and Advanced Manufacture, Department of Anethesiology, School of Stomatology, Fourth Military Medical University, Xi'an, China, 2 Shaanxi Key Laboratory of Ischemic Cardiovascular Disease, Institute of Basic and Translational Medicine, Xi'an Medical University, Xi'an, China, ${ }^{3}$ Department of Preventive Medicine, School of Stomatology, Fourth Military Medical University, Xi'an, China, ${ }^{4}$ Shaanxi Key Laboratory of Brain Disorders \& Institute of Basic and Translational Medicine, Xi'an Medical University, Xi'an, China, ${ }^{5}$ Institution of Basic Medical Science, Xi'an Medical University, Xi'an, China

Abnormal gene expression and secreted protein levels are accompanied by extensive pathological changes. Secreted frizzled related protein (SFRP) family members are antagonistic inhibitors of the Wnt signaling pathway, and they were recently found to be involved in the pathogenesis of a variety of metabolic diseases, which has led to extensive interest in SFRPs. Previous reports highlighted the importance of SFRPs in lipid metabolism, obesity, type 2 diabetes mellitus and cardiovascular diseases. In this review, we provide a detailed introduction of SFRPs, including their structural characteristics, receptors, inhibitors, signaling pathways and metabolic disease impacts. In addition to summarizing the pathologies and potential molecular mechanisms associated with SFRPs, this review further suggests the potential future use of SFRPs as disease biomarkers therapeutic targets.

Keywords: SFRPs, adipocyte, obesity, metabolism disease, cardiovascular disease

\section{INTRODUCTION}

Metabolic syndrome (MetS) is a global epidemic that causes heavy social and economic burdens (1), and it consists of a group of cardiovascular risk factors, including dyslipidemia, glucose metabolism disorders, visceral obesity and hypertension (2). The risk of cardiovascular disease is directly proportional to the components of MetS, including the occurrence of coronary heart disease (CHD), atherosclerotic cardiovascular disease and type 2 diabetes mellitus (T2DM) (2). Central obesity,

\footnotetext{
Abbreviations: Akt, protein kinase B; BMP, bone morphogenetic protein; BMI, body mass index; CHD, coronary heart disease; CRD, cysteine rich domain; Dvl, disheveled; EAT, epicardial adipose tissue; ECs, endothelial cells; Fzd, frizzled; GSK3 $\beta$, glycogen synthase kinase 3 beta; HEK293, human embryonic kidney; IR, insulin resistance; JNK, c-Jun N-terminal Kinase; KDM4A, Lysine demethylase 4a; MetS, Metabolic syndrome; MSCs, mesenchymal stem cells; NTR, netrin-like domain; PCP, pathway and planar cell polarity; SFRP, secreted frizzled related protein; STEMI, ST segment elevation myocardial infarction; T2DM, type 2 diabetes mellitus.
} 


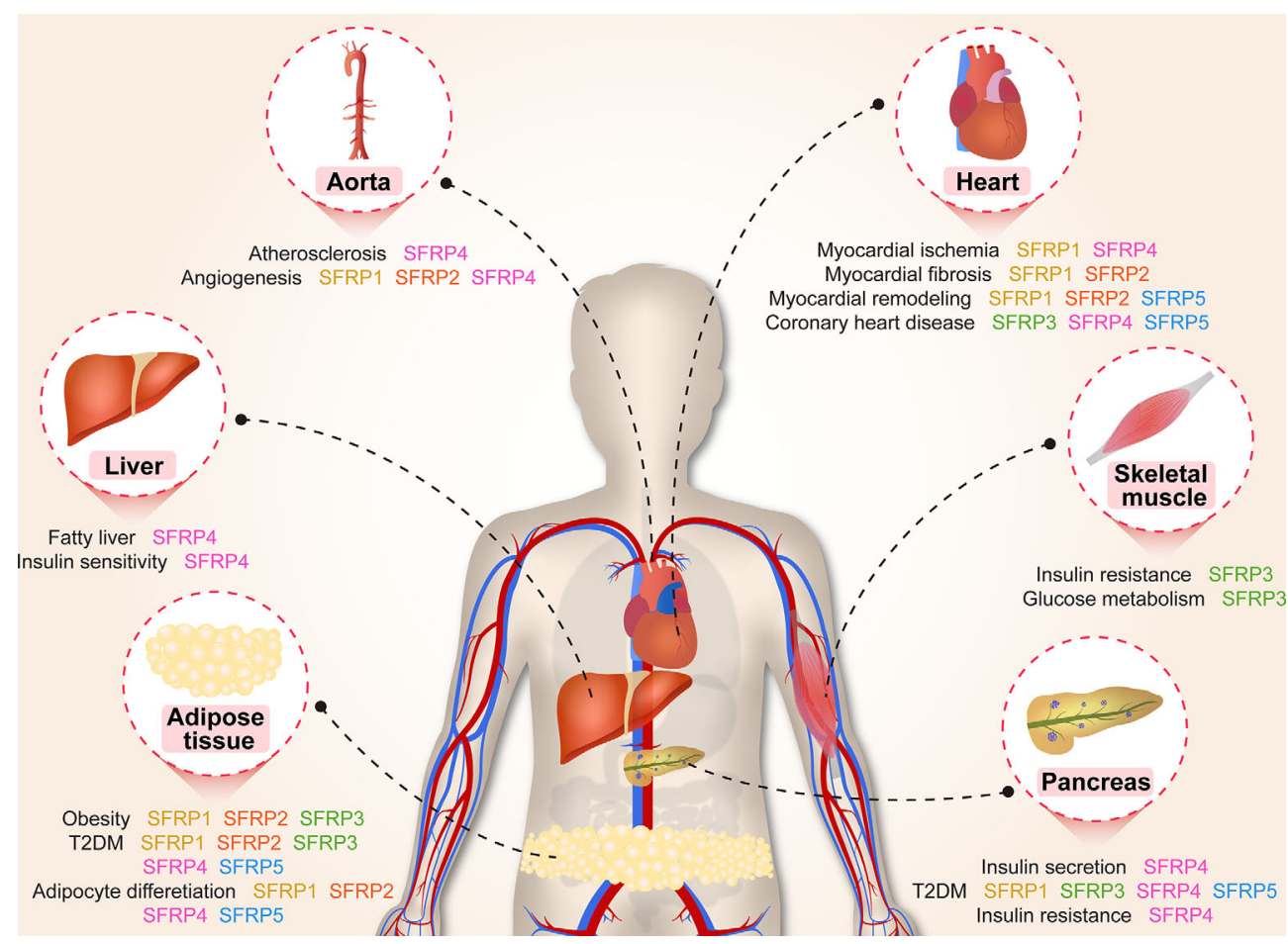

GRAPHICAL ABSTRACT

elevated blood pressure, dyslipidemia, elevated fasting blood glucose and insulin resistance (IR) are the core manifestations of the syndrome (3).

In 1973 while screening mutations for visual phenotypes, Sharma reported that the wingless gene affects the development pattern of Drosophila (4). Subsequently, a series of experimental studies revealed that Wnt family signaling proteins are critical for morphological development of individual embryos, including central nervous system, control of asymmetric cell division and tissue polarity (5). Wnt signal transduction is regulated by a variety of effectors, including agonists and antagonists, which fine tunes Wnt signaling to regulate intracellular signal transduction and/or extracellular ligand receptor interaction $(6,7)$.

With the gradual discovery of Wnt proteins, a secreted protein that binds to Wnt protein and inhibits its function was identified and named secreted frizzled related protein (SFRP) due to its high similarity with the extracellular receptor domain of frizzled (Fzd) (4). To date, five SFRP members have been identified and named SFRP1-5, all of which bind specifically with Wnt ligands (8). Multiples studies identified SFRPs as important regulators of MetS, including adipocyte differentiation, lipid metabolism, diabetes and cardiovascular diseases (9-11). In this review, we focus on the new findings implicating SFRPs in the development of metabolic diseases. We describe the structure, function, signal transduction pathways of SFRPs and their new identified functions in lipid metabolism and cardiovascular disease.

\section{THE CHARACTERISTIC AND EXPRESSION PATTERN OF SFRPS}

\section{The Structural Characteristic of SFRPs}

In 1997, Ratter et al. discovered a family of mammalian genes which encodes secretion related proteins (4). These proteins are homologous to the cysteine rich ligand binding domain found in the Fzd transmembrane receptor family (4). SFRPs contain three structural units: an amino terminal signal peptide, a coiled cysteine rich domain (CRD) and a carboxyl terminus netrinlike domain (NTR) (12). The CRD spans about 120 amino acids and contains 10 conserved cysteine residues, and it presents approximately $30-50 \%$ sequence similarity with the CRD of the Fzd receptor (13). The NTR consists of six cysteine residues, several conserved hydrophobic residues and secondary structures (14). The conserved domains and structural characteristic details of SFRP1-5 are shown in Figure $\mathbf{1 .}$

The CRD region of SFRP1 contains 10 conserved cysteine residues and forms 5 disulfide bonds. Deletion of 48 amino acids (d115-163) in CRD region decreased its activity by $75 \%$ and deletion of 92 amino acids (d71-163) resulted in complete loss of SFRP1 function, suggesting the conserved domain is essential for SFRP1 biological function (13). In addition, the motif L/VVDGRW-L/V and DGR constitute the core of the SFRP1 binding motif, indicating that proteins containing DGR motifs may be new binding partners of SFRP1 (15). Moreover, the pocket finder was used to determine the active sites of SFRP4, including site 1 containing the amino acids, which are essential 


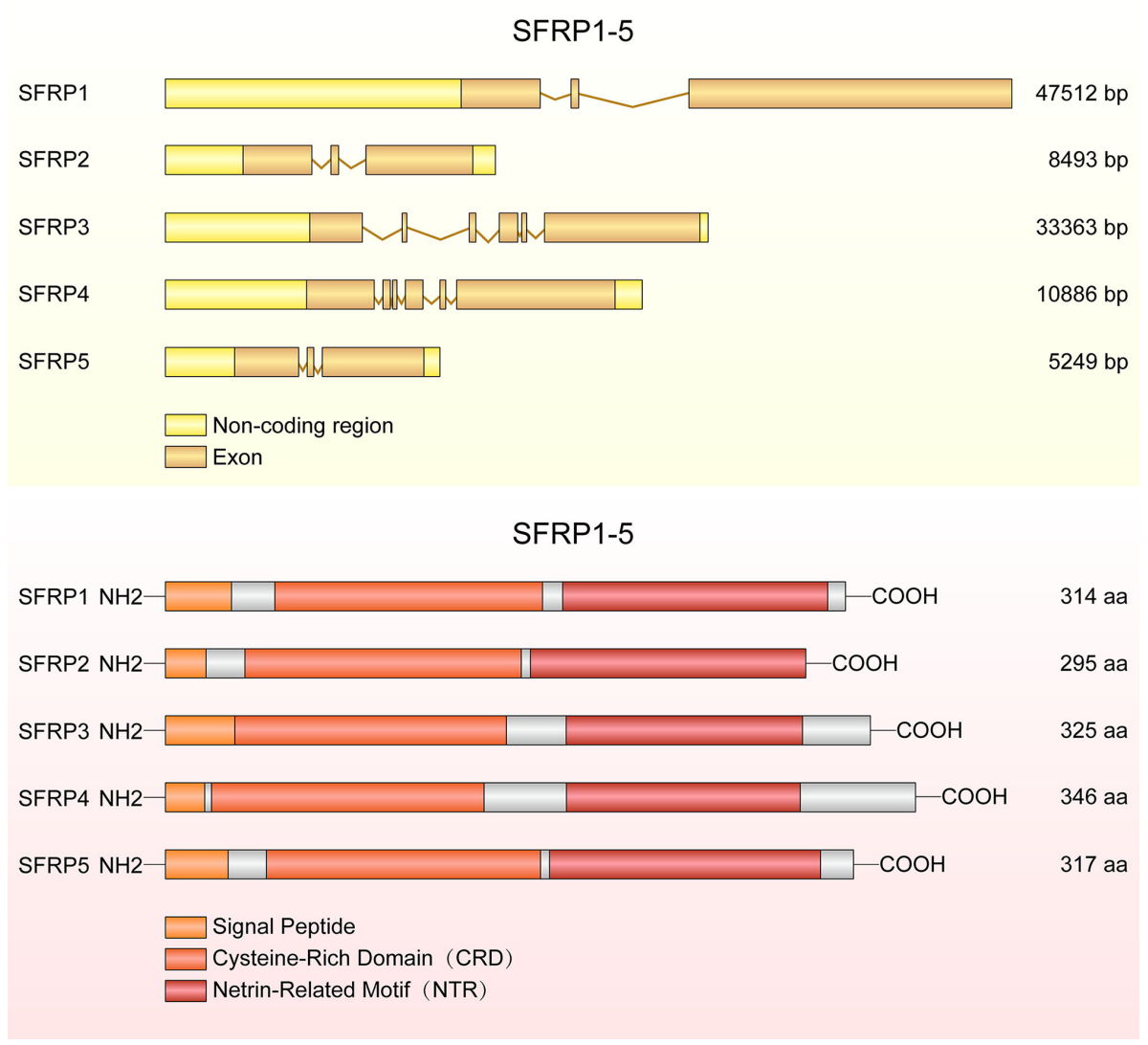

FIGURE 1 | The structure of SFRP genes and proteins. The diagram shows SFRP1, SFRP2 and SFRP5 each containing three exons, but SFRP3 and SFRP4 containing six exons. SFRPs have common structural features with a signal peptide comprising 20-30 amino acids, a cysteine rich domain (CRD) and a netrin like domain (NTR).

for suppressing the secretion of insulin (16). Four splice variants of SFRP4 were identified and the transcripts of all splice variants are similar at the 5 ' end but different at the $3^{\prime}$ end. Markedly, the tissue distribution of the splice variants was different, suggesting that these splice variants of SFRP4 have specific overlapping functions in different tissues (17). Previous studies reported a total of 15 SFRP5 mutants, including 10 bearing nonsynonymous amino acid mutations with variation frequencies closely related to the obesity phenotype (18).

In silico analyses of amino acid sequences reveal three subgroups of SFRPs: SFRP1/SFRP5, SFRP2 and SFRP3/SFRP4 $(12,19)$. However, sequence homology and phylogenetic tree analyses showed that SFRP1, 2 and 5 form a subgroup apart from SFRP3 and 4 (13). This cluster analysis also reflects differential gene expression of SFRPs in tissues. SFRP1, SFRP2 and SFRP5 are in different horizontal groups of the same chromosome, while SFRP4 and SFRP3 do not belong to this group. A third subgroup of SFRPs was found in Xenopus laevis, chicken and zebrafish but not in mammals. The members of this subgroup include sizzled, sizzled 2 and crescent, which share the same sequence similarity with the SFRP1, SFRP2 and SFRP5 subgroups (20). Excitingly, tyrosine 73 of SFRP1 plays a key role in antagonizing Wnt and is conserved in the closely related SFRP1, SFRP2 and SFRP5 but replaced by tryptophan in SFRP3 and SFRP4 (13). Previous studies demonstrated that heparin inhibits tyrosine sulfation of SFRP1, and a sequence analysis demonstrates that tyrosine sulfation is highly conserved in SFRP1 and SFRP5, but not in SFRP2, SFRP3 and SFRP4 (21). Hence, the tyrosine 73 is the key tyrosine residue that binds the Fzd receptor and antagonizes the Wnt signaling pathway, whereas SFRP1 accumulates in cells and is more stability when it inhibits posttranslational modifications by inhibiting the tyrosine sulfation. Protein structure determines biological function during cell metabolism and development, proteins with similar structure are more similar in function, the following review will elaborate in detail.

\section{Expression Pattern of SFRPs}

The differential tissue-specific expression of SFRPs in humans was verified by RNA sequencing (22). SFRP1 is ubiquitously expressed in almost all tissues, with high levels in the endometrium, fat tissue, gallbladder, heart, kidney, prostate, testis, urinary bladder and moderate levels in the ovary, may contribute to the development of reproductive system development and germ cell maturation $(23,24)$. SFRP2 is highly expressed in the urinary bladder, gallbladder, fat tissue and esophagus; moderately expressed in skin, small intestine, 
colon and appendix; not detected in heart, kidney, liver and spleen, suggesting that SFRP2 participates in the regulation of biological processes that include cell proliferation, differentiation, apoptosis, and cell localization (24). SFRP3 is expressed in almost all tissues with high levels in spleen, gall bladder, and low levels in fat tissue, bone marrow, liver and pancreas, indicating SFRP3 may be related to human immunity and the formation of immune cells (24). SFRP4 is highly expressed in the female reproductive system, such as the endometrium and ovary, moderately expressed in fat tissue, heart and urinary bladder, indicating that SFRP4 is related to female reproduction and development $(24,25)$. SFRP5 is highly expressed in duodenum, pancreas, small intestine, moderately expressed in the lungs, liver, gall bladder, adrenal, prostate and stomach, and dysregulation of SFRP5 in pancreas contributes to insulin secretion or glucose metabolism disease (24).

SFRPs gene expression profiles were examined in the pancreas of mice at E12-E17, P0 and P7 (26). The level of SFRP1 was high at E12-E14 and then decreased. The expression of SFRP2 started to show at E12, peaked at E14 and then decreased. SFRP3 was expressed at low levels during development and remained unchanged. SFRP4 was expressed at very low levels during development but peaked at P7, suggesting that the expression pattern of SFRPs in the pancreas is varies during the mouse embryonic development (26).

\section{Receptor and Inhibitors of SFRPs}

SFRPs promote or inhibit Wnt/ $\beta$-catenin signaling pathway, depending on the cell environment, concentration and Fzd receptor expression pattern (27). For example, SFRP1 and SFRP2 inhibit the activity of Wnt3a and regulate the development of the dorsal neural tube (28). Whereas SFRP2 enhances Wnt3adependent low density lipoprotein receptor related protein 6 phosphorylation, $\beta$-catenin protein accumulation and nuclear translocation in human embryonic kidney (HEK293) cells (29). Additionally, Fzd5 enhances the activity of SFRP1 stimulated Wnt3a in L cells while SFRP2 enhances Wnt3a activity in a dosedependent manner in HEK293, C57MG and L cells (30). Retinoic acid extracted from vitamin $\mathrm{A}$ is essential for mammalian development, and vitamin A deficiency results in significantly reduced expression levels of SFRP1 in embryos (31). In addition, sequence and structure bioinformatics analysis tools are successful at predicting the potential inhibitors of SFRP4, including cycloformylhydrazide, clopramide and perindopril (16).

\section{Wnt SIGNALING PATHWAY}

Wnt signaling has three typical pathways: canonical Wnt/ $\beta$ catenin signaling pathway that controls cell fate determination and two non-canonical pathways that control cell movement and tissue polarity, namely, the $\mathrm{Wnt} / \mathrm{Ca}^{2+}$ signaling pathway and planar cell polarity (PCP)/non-canonical c-Jun N-terminal kinase (JNK) signaling pathway $(32,33)$ (Figure 2).

In the canonical $W n t / \beta$-catenin pathway, Wnts bind to the membrane receptor Fzd to inactivate the $\beta$-catenin degradation complex that consists of adenomatous polyposis coli/Axin/glycogen

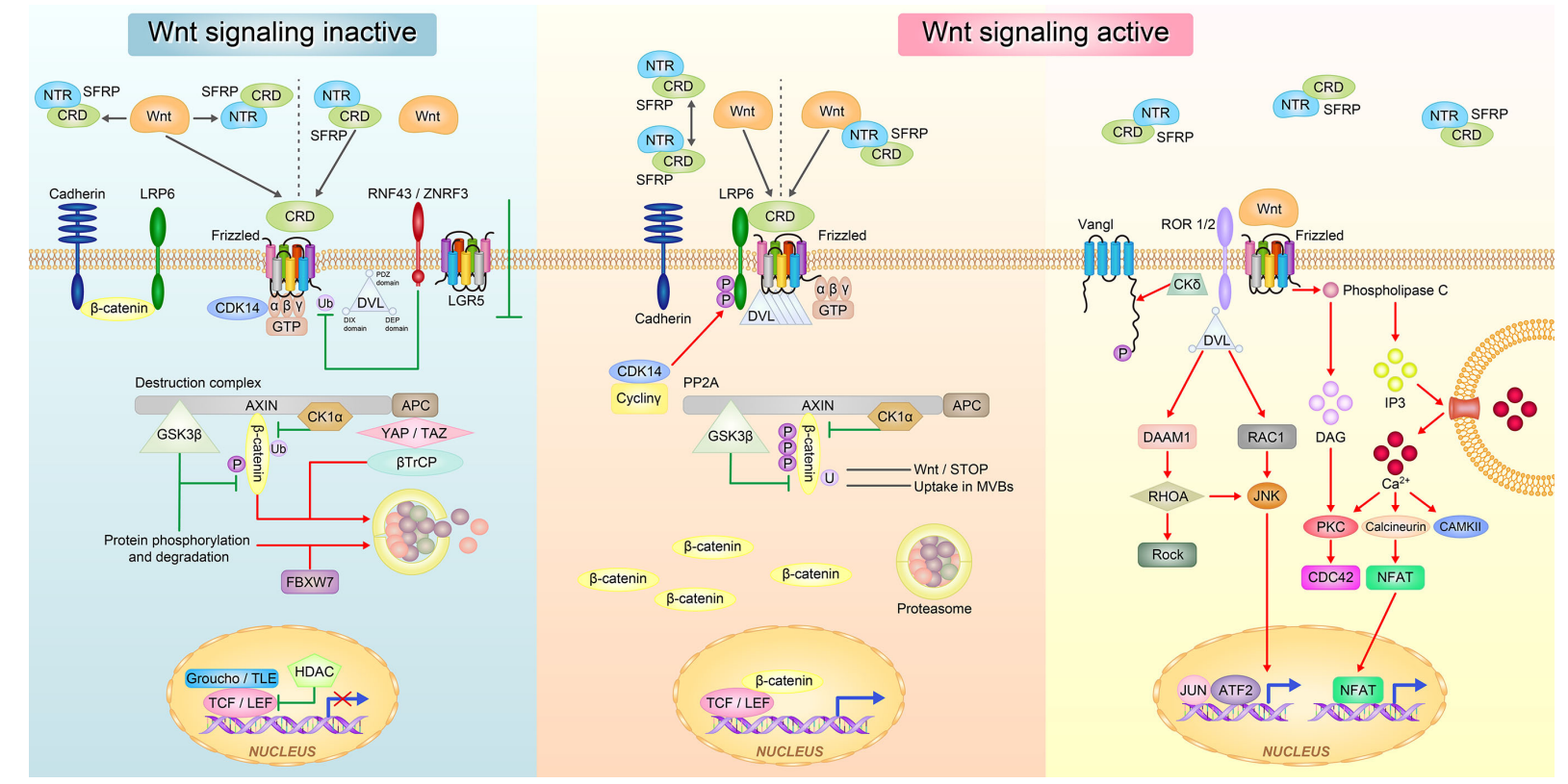

FIGURE 2 The Wnt signaling pathway regulated by SFRPs. In the inactive state of Wnt, SFRPs sequestered Wnt proteins via either CRD or NTR domain and prevent them from binding to the frizzled receptor. SFRPs can also bind to Frizzled receptor via CRD domain to block Wnt signal transduction (left). In the active state of Wnt, SFRPs form inactive complexes by their own and Wnt proteins directly bind to Frizzled receptor; or SFRPs form complex with Wnts and interact with Frizzled receptor to promote Wnt signal transduction (right). The Wnt proteins then activate at least three different downstream signaling pathways: the canonical Wnt- $\beta$-catenin, the non-canonical planar cell polarity (PCP) and the $\mathrm{Wnt}^{-\mathrm{Ca}^{2+}}$ pathways. 
synthase kinase 3 beta (GSK3 $\beta$ ) through disheveled (Dvl). During this process, $\beta$-catenin is not phosphorylated at specific serine and threonine residues, and it dissociates form the complex, binds to the $\mathrm{T}$ cell factor family of proteins, and translocates to the nucleus to transactivate target genes such c-myc and Cyclin-D1. In the absence of Wnt, $\beta$-catenin is phosphorylated by GSK3 $\beta$ or casein kinase and presented to the $\beta$-transduction repeat containing protein adenomatous polyposis coli/Axin proteins for ubiquitin mediated proteasomal degradation. For example, overexpression of SFRP4 promoted human adipose tissue derived mesenchymal stem cells differentiation and lipid accumulation by antagonistic inhibition of the Wnt/ $\beta$-catenin signaling pathway activated by Wnt3a (34).

In the $\mathrm{Wnt} / \mathrm{Ca}^{2+}$ signaling pathway, Wnts bind to Fzd to activate Dvl, which leads to an increase in intracellular $\mathrm{Ca}^{2+}$ and the activation of protein kinase $\mathrm{C}$ in response to distinct groups of Wnt ligands and Fzd receptors. Increased intracellular $\mathrm{Ca}^{2+}$ leads to a secondary activation of protein kinase $\mathrm{C}$ and calmodulin kinase II (35). For example, when identifying the role of SFRP4 in islet cells, we discovered that overexpression of SFRP4 activates the $\mathrm{Ca}^{2+}$ signaling pathway, enhances endocytosis, weakens exocytosis and decreases insulin secretion in islet cells (36).

The Wnt/PCP JNK signaling pathway uses Fzd and Dvl, but does not cause GSK-3 $\beta$ stabilization or calcium influx to regulate planar cell polarity (37). In vertebrates, Wnt/PCP signaling is thought to control polarized cell movements during gastrulation and neurulation (37). Wnt11 combined with fzd7 regulates projejunal motility in vertebrates, SFRP5 antagonizes the effect of Wnt5a in adipose tissue and activates the Wnt/PCP JNK signaling pathway by binding membrane receptors (38).

\section{EFFECT OF SFRPs ON METABOLIC DISEASE}

Adipocyte differentiation is closely related to glucose and lipid metabolism and regulates IR, T2DM and hyperlipoidemia (39). Adipogenesis is a tightly regulated cellular process involving multiple transcription factors and signaling pathways, including the Wnt signaling pathway and regulators of SFRPs (40). For example, SFRP1, SFRP2 and SFRP4 are adipokines, which related to insulin sensitivity and affect the secretion of interleukin-1, monocyte chemoattractant protein-1 and adiponectin (41). The regulation of adipocyte differentiation by SFRPs is shown in Figure 3.

\section{Adipocyte Differentiation}

The functions of adipose tissue include lipid storage, energy balance and the sharing of insulin and other hormone signals. Adipogenesis is a process in which adipocytes develop from adipose tissue derived progenitor cells into adipose tissue (42). A series of studies have shown that SFRP1 contributes to adipogenesis in multiple cells. Overexpression of SFRP1 promotes 3T3-L1 cell differentiation in response to extracellular Wnt inhibitors (9). Conversely, SFRP1 deficiency inhibits adipogenesis and body fat in aged male mice (43).
Moreover, SFRP1 mRNA expression dramatically increases in Grave's ophthalmopathy caused by inflammation and an increased volume of the orbital adipose tissue (44). Meanwhile, inhibition of the Wnt/ $\beta$-catenin singling pathway by Dac1 knockdown reversed SFRP1 induced impairment of adipogenesis (45), suggesting that SFRP1 is a negative regulator of adipose differentiation. The potential molecular mechanism involves GSK3 (an upstream regulator) activation of the signal transducer and activator of transcription 5 by phosphorylation, which then binds and regulates the SFRP1 promoter, coordinately modulates adipogenic regulator expression and antagonizes canonical Wnt signaling induced adipogenesis (46). These results provide insights on the molecular mechanism of adipogenesis and provide an evidence that different adipogenic regulators coordinately modulate adipocyte differentiation. Understanding the signaling pathways that mediate trans-differentiation between myoblasts and adipocytes is important to develop therapeutics for treatment of obesity and impaired metabolism (47). As a molecular switch between osteoblasts and adipogenesis in bone marrow, SFRP1 plays an important role as an autocrine and paracrine signaling molecule in mesenchymal stem cells (MSCs) or progenitor cells (48). For example, treatment of mouse bone marrow stromal cells with recombinant SFRP1 inhibits osteoblast differentiation of ST2 cells and promotes adipogenic differentiation in a dose-dependent manner $(34,49)$. Meanwhile, cyclic mechanical stretch inhibited myoblast transdifferentiation into adipocytes whereby SFRP2 treatment completely eliminated the inhibition of mechanical stretch on adipogenesis (50).

Our research indicates that SFRP4 expression during adipocyte differentiation is complex and varies among different tissues. Body size acquisition was contributed by depot-specific in adipose tissues and fat accumulation, as SFRP4 induces adipocyte maturation derived from visceral adipose tissue, meanwhile adipocytes from subcutaneous adipose tissue responds differently (51). Additionally, activation of Wnt signaling via knockdown of SFRP4 inhibits adipogenesis while the treatment with SFRP4 induces a 1.5-fold increase in lipid accumulation in human adipose derived mesenchymal stem cells $(34,52)$, these findings demonstrate an interaction between Wnt antagonism and Wnt activation during adipogenesis. As well known, Lysine demethylase 4a (KDM4A) is a novel epigenetic regulator of osteoblast and adipocyte differentiation that directly binds to the promoter of SFRP4, removes the histone methylation marker $\mathrm{H} 3 \mathrm{~K} 9 \mathrm{ME} 3$, and reduces the DNA methylation of $\mathrm{CpG}$ in the promoter region of SFRP4. Concordantly, silencing of SFRP4 abolished the inhibition of KDM4A on osteogenic differentiation and the promotion of adipogenic differentiation induced by typical Wnt signal, these data have identified KDM4A as an upstream epigenetic regulator of SFRP4 in osteoblast and adipocyte differentiation (53).

In the early stage of 3T3-L1 preadipocytes, SFRP5 expression gradually increases at the start of preadipocyte differentiation. However, SFRP5 expression decreases significantly upon treatment with differentiation medium, indicating that SFRP5 expression is depend on the differentiation of adipocytes, maybe 
SFRPs regulate lipid metabolism
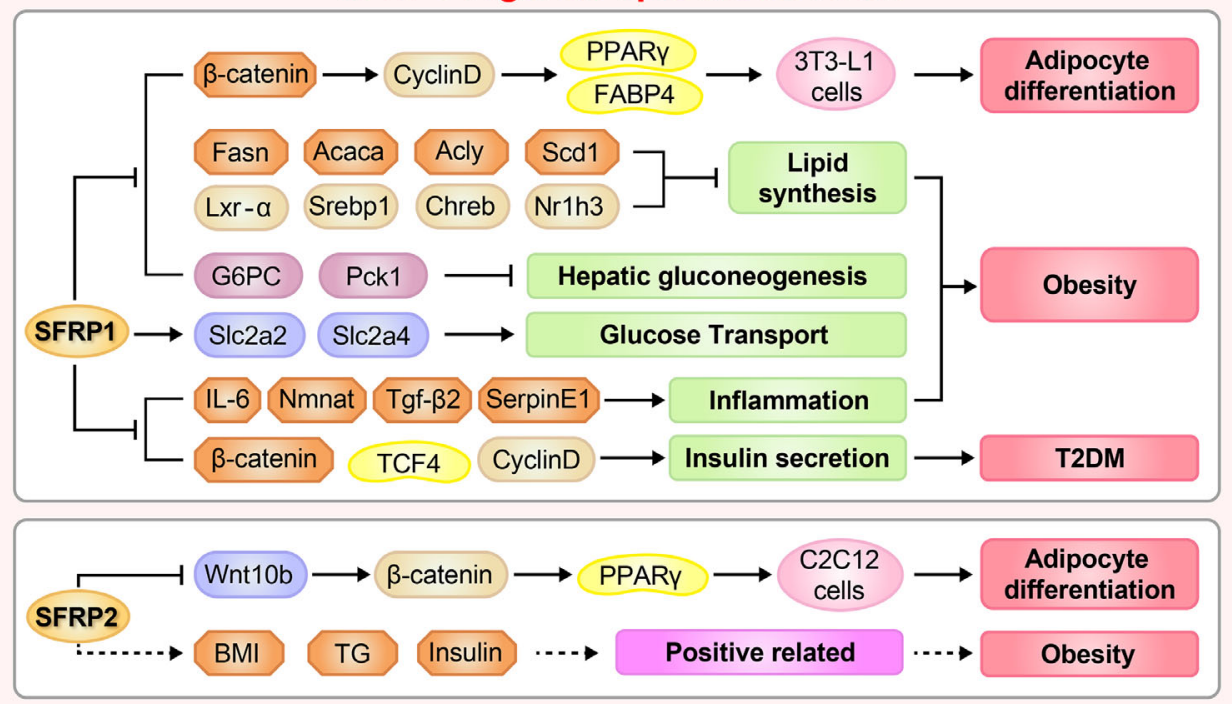

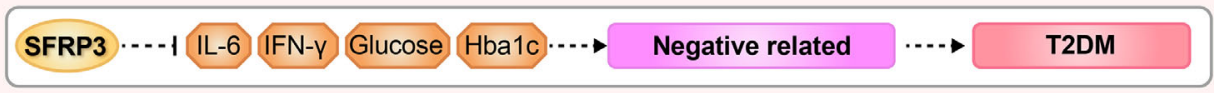
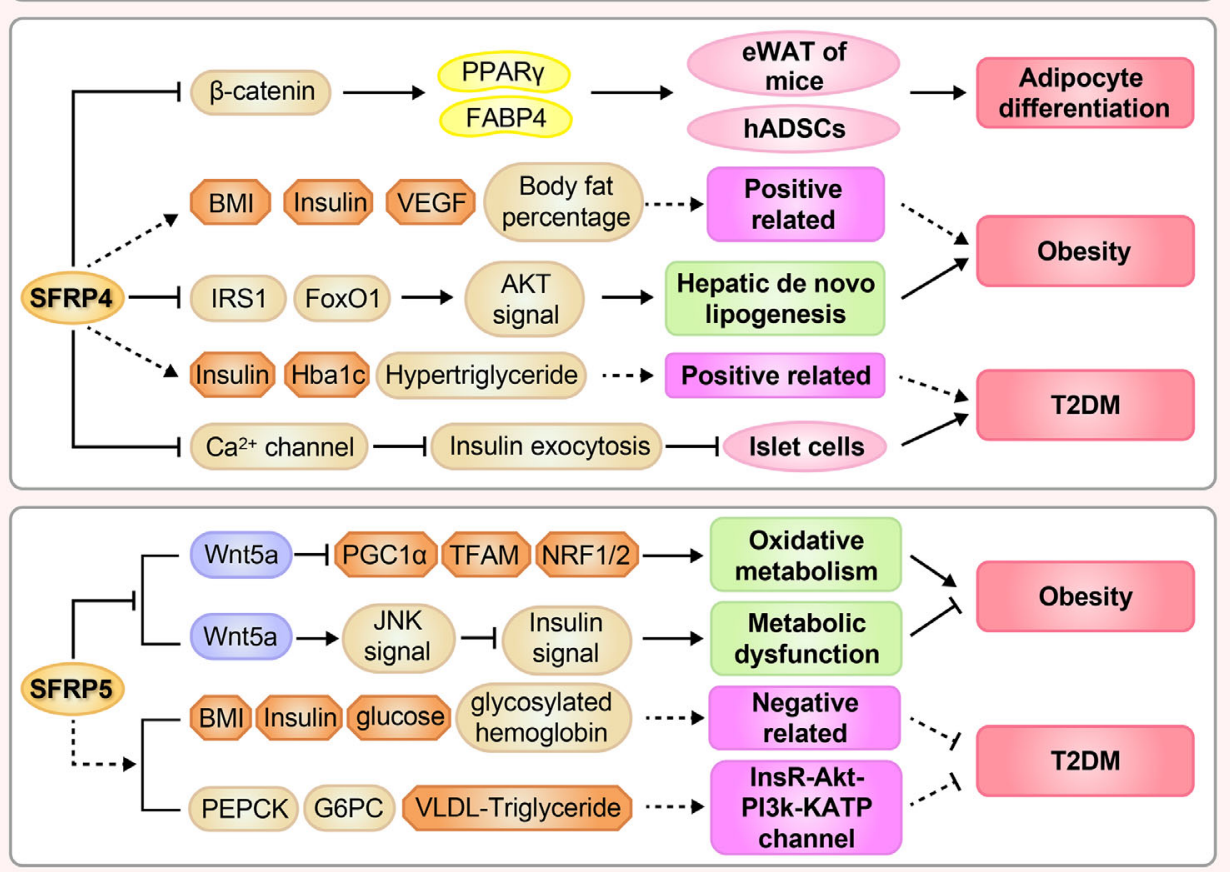

$\longrightarrow$ Up-regulate $\quad \longrightarrow$ Down-regulate $\quad$ Direct effect $\quad \ldots . .$. Indirect effect

FIGURE 3 | A brief overview of the molecular mechanisms by which SFRPs regulate lipid metabolism and cardiovascular disease. The figure shows the potential mechanisms by which how SFRPs modulate adipocyte differentiation, obesity and type 2 diabetes mellitus (T2DM). Acaca, acetyl-Coenzyme A carboxylase alpha; Acly, ATP citrate lyase; Akt, AKT serine/threonine kinase 1; Rho, rhodopsin; BMl, body mass index; Chreb, cAMP responsive element binding protein; FABP4, fatty acid binding protein 4; Fasn, fatty acid synthase; Foxo1, forkhead box 01; G6PC, glucose-6-phosphatase, catalytic; hADSCs, adipose mesenchymal stem cells; Hba1c, Glycosylated hemoglobin; IFN- $\gamma$, interferon- $\gamma$; IL-6, leukotriene-6; IRS1, insulin receptor substrate 1; Lxr- $\alpha$, LexA regulated function- $\alpha$; Nmnat, Nicotinamide mononucleotide adenylyltransferase; Nr1h3, nuclear receptor subfamily 1 group H member 3; NRF1/2, nuclear respiratory factor 1/2; Pck1, phosphoenolpyruvate carboxykinase 1, cytosolic; PCP, Pupal cuticle protein; PEPCK, phosphoenolpyruvate carboxykinase; PPAR $\gamma$, peroxisome proliferator activated receptor- $\gamma$; BNP, natriuretic peptides A-like; Scd1, stearoyl-Coenzyme A desaturase 1; SerpinE1, serpin family E member 1; SFRP1, secreted frizzled related protein1; Slc2a2/4, solute carrier family 2 (facilitated glucose transporter), member 2/member4; Srebp1, sterol regulatory element binding protein 1; TCF4, transcription factor 4; TFAM, transcription factor A, mitochondrial; TG, triglyceride; Tgf- $\beta 2$, transforming growth factor $\beta$ 2; VEGF, vascular endothelial growth factor. 
is a key regulator to improve insulin sensitivity by rosiglitazone or metformin in adipocyte (54). Remarkably, increasing doses of recombinant SFRP5, a competitive inhibitor of $\mathrm{Wnt5}$ a receptor, blocks the dedifferentiation of adipocytes when added to the coculture medium (55). Subsequently, Zeng et al. revealed that SFRP5 promoter region (-2284 to $-2263 \mathrm{bp})$ was under the transcriptional regulation of peroxisome proliferator-activated receptor gamma and is activated in 3T3-L1 adipocytes (56). Nevertheless, there is no significant difference in serum SFRP5 levels between obese and non-obese subjects, suggesting that SFRP5 exists only as a marker of mature adipocytes and does not regulate adipocyte differentiation (57).

\section{Obesity}

SFRP1 increases in response to initial weight gain and decreases under conditions of extreme obesity in both humans and animals. Administration of high fat diet to SFRP1 knockout mice disturbs glucose homeostasis, induces inflammation and aberrantly elevates regulators of hepatic gluconeogenesis resulting in exacerbated weight gain, provide a new perspective that SFRP1 is a critical factor required for maintaining appropriate cellular signaling in response to the onset of obesity (43).

SFRP2 is highly expressed in omental adipose tissue compared to subcutaneous adipose tissue, and positively correlated with plasma insulin and body mass index (BMI). SFRP2 is expressed significantly in patients with impaired glucose tolerance compared to normal controls $(34.2 \mathrm{ng} / \mathrm{mL} v s$. $29.5 \mathrm{ng} / \mathrm{mL}$ ) (58). However, diet induces significant changes in fat metabolism and SFRP2 expression in subcutaneous adipose tissue, indicating that weight loss regulates the expression of genes related to metabolic diseases in adipose tissue (59).

Previous study demonstrated that dietary macronutrients regulate insulin sensitivity and energy consumption, for example, the proportion of carbohydrate content is related to liver insulin sensitivity and does not affect serum SFRP4 level. This type of regulation suggests that dietary changes do not regulate the expression level of SFRP4 in serum (60). However, circulating SFRP4 in obese individuals is significantly higher than normal individuals, and is associated with body fat percentage, insulin sensitivity, vascular endothelial growth factor in abdominal subcutaneous adipose tissue, suggesting that abdominal subcutaneous adipose tissue maybe the main contributor of circulating SFRP4 (61). The increase of SFRP4 in visceral adipose tissue of obese men reduces the insulin receptor substrate 1 and fork head box $\mathrm{O} 1$ protein abundance in hepatocytes and inactivates protein kinase B (Akt) signaling pathway, resulting in fat breakdown in the liver and aggravated IR. Thus, SFRP4 may be an attractive target for alleviating the pathological development of type 2 diabetes and fatty liver (62).

SFRP5, an inhibitor of Wnt signaling, is tightly associated with obesity and weight gain in mice (63). SFRP5 is secreted by adipocytes and regulates the micro-environment of white adipose tissue under metabolic stress stimulation. First, Rulifson et al. reported that overexpression of SFRP5 increases fasting glucose and insulin levels and significantly impairs glucose intolerance in diet induced obese mice (64).
Second, SFRP5 is significantly elevated in adipocytes during obesity, including $\mathrm{db} / \mathrm{db}, \mathrm{ob} / \mathrm{ob}$ and high fat diet-fed mice. Meanwhile, SFRP5 deficiency resisted to diet induced obesity by stimulating mitochondrial oxidation activity and increasing SFRP1 compensation, which is mediated in part by peroxisome proliferator-activated receptor gamma coactivator 1 alpha and mitochondrial transcription factor A $(65,66)$. Third, obesity related complications also occurred in obese patients with low SFRP5 levels and pro-inflammatory infiltration of visceral tissue (67). Conversely, SFRP5 knockout mice did not exhibit a detectable phenotype when given normal food. However, administering a high calorie diet induces fat pad inflammation and systemic metabolic dysfunction, which is believed to be resulting from inhibition of JNK activation in macrophages and adipocytes via paracrine and autocrine mechanisms, respectively $(38,63)$. One important reason for this discrepancy may lie in differences between the construction sources of mice in contrast to mouse models in virous experiment. Furthermore, the phenotypes of obesity and diabetes in inbred mice with SFRPS homologous genes were significantly different (Table 1), for instance, there was no difference in SFRP5 expression levels in DBA/2J mice fed with high-fat diet, but almost 20 times higher in C57BL/6 mice, indicating that epigenetics regulate the phenotypes of obesity and fat swelling of inbred mice and this needs further investigation (107). In addition to studies using obesity animal model, the ratio of plasma Wnt5a/SFRP5 in obese patients is considered to be a more accurate evaluation index, which indicates that the decrease of SFRP 5 concentration may be a direct factor leading to cardiovascular disease in obese patients (108). Fortunately, SFRP5 monoclonal antibody treatment significantly improved insulin sensitivity, restored islet $\beta$ cell function and increased pro-insulin and C-peptide levels (64), which are consistent with those observed in the SFRP5 ${ }^{\text {Q27stop }}$ mice described by Mori et al. (65).

\section{Diabetes and IR}

Adipose tissue, as an endocrine organ, secretes more than 300 cytokines to regulate the response of target cells including islet $\beta$ cells (109). It has been reported that overexpression of SFRP1 inhibited the insulin secretion from islet cells which are cocultured with human adipocytes (110). Otherwise, muscle SFRP3, acting as a new type of insulin sensitizer, negatively correlated with circulating inflammatory factors and positively correlated with insulin sensitivity, is expressed at low levels in skeletal muscles and serum of pre-diabetes and T2DM patients compared to healthy subjects (111).

Multiple clinical studies proved that SFRP4 is involved in the occurrence and development of T2DM, as elevated serum SFRP4 puts patients at three-folds higher risk of developing diabetes (10, 112-115). Serum SFRP4 concentration is independently and positively correlated with insulin, glycosylated hemoglobin, fasting triglyceride and hypertriglyceridemia levels (10, 113115). Moreover, circulating SFRP4 and renin are significantly higher in gestational diabetes mellitus patients than healthy subjects. In addition SFRP4 and renin levels are positively correlated (116). Compared with the healthy individuals, patients with polycystic ovary syndrome showed higher levels 
TABLE 1 | The overview of SFRPs knockout mice: Function and signaling pathways.

\begin{tabular}{|c|c|c|c|}
\hline Genotype & Function & Signaling pathway & References \\
\hline SFRP1 ${ }^{-/-}$ & $\begin{array}{l}\text { 1. Enhances trabecular bone formation in adults. } \\
\text { 2. Telencephalic Patterning, growth and differentiation. } \\
\text { 3. Promotes normal alveolar formation in lung development. } \\
\text { 4. Enhances mammary gland inflammation in response to obesity } \\
\text { 5. Mediates mammary epithelial apoptotic response to DNA damage. } \\
\text { 6. Maintains proper mammary gland development. } \\
\text { 7. Improves fracture healing } \\
\text { 8. Regulates the tumors progression in murine mammary epithelial cells. } \\
\text { 9. Regulates the progression of renal fibrosis. } \\
\text { 10. Regulates cycling activity and maintenance of hematopoietic stem cells. } \\
\text { 11. Leads to deterioration of cardiac function in aged mice. } \\
\text { 12. Regulates the cancer stem cells proliferation and metastasis in skin cancer. } \\
\text { 13. Contributes to the development of brain, kidney and skeleton. }\end{array}$ & $\begin{array}{l}\text { 1. Wnt signaling in osteoblasts } \\
\text { 2. Wnt and Notch signaling in hippocampal. } \\
\text { 3. Wnt and ERK signaling in lung tissue. } \\
\text { 4. Wnt and apoptosis in breast cancer of obesity. } \\
\text { 5. P53 target genes pathway in mammary epithelial cells. } \\
\text { 6. Wnt and downstream regulators in mammary gland. } \\
\text { 7. Wnt signaling in bone formation. } \\
\text { 8. Wnt and TGF } \beta \text { signaling pathway. } \\
\text { 9. Non-canonical Wnt/PCP pathway. } \\
\text { 10. Extrinsic regulation of } \beta \text {-catenin. } \\
\text { 11. Wnt signaling pathway in cardiac tissue. } \\
\text { 12. EMT regulators and growth factor signaling. } \\
\text { 13. Wnt signaling pathway. }\end{array}$ & $(68-80)$ \\
\hline $\mathrm{SFRP}^{-/-}$ & $\begin{array}{l}\text { 1. Contributes to the development of primary aldosteronism. } \\
\text { 2. Controls fibrosis in myocardial infarction. } \\
\text { 3. Plays a critical role in proper distal limb formation. } \\
\text { 4. Modulates cell fate of the murine intestinal epithelium }\end{array}$ & $\begin{array}{l}\text { 1. Wnt signaling pathway. } \\
\text { 2. Enhanced procollagen C-proteinase activity. } \\
\text { 3. Wnt/ } \beta \text {-catenin signaling pathway. } \\
\text { 4. Wnt/ } \beta \text {-catenin signaling pathway }\end{array}$ & $(81-84)$ \\
\hline $\mathrm{SFRP3}^{-/-}$ & $\begin{array}{l}\text { 1. Controls post-natal mammary gland morphogenesis. } \\
\text { 2. modulates the progressive weakness and muscle degeneration. } \\
\text { 3. As a molecular target of antidepressant treatments in rodent models. } \\
\text { 4. Regulates cell development of articular cartilage - subchondral bone unit. } \\
\text { 5. Contributes to the development of osteoarthritis. } \\
\text { 6. Reduces voluntary running exercise performance in mice. } \\
\text { 7. Regulates quiescent adult hippocampal neural stem cell activation. } \\
\text { 8. Promotes the osteogenesis }\end{array}$ & 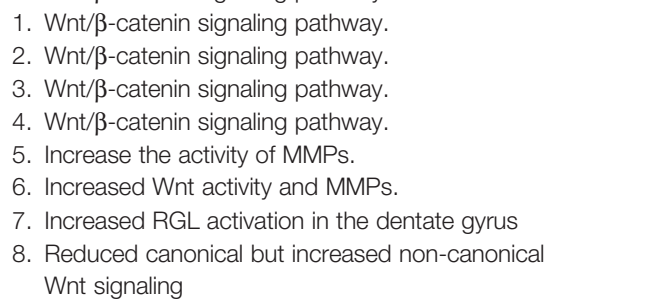 & $(85-92)$ \\
\hline SFRP4 ${ }^{-/-}$ & $\begin{array}{l}\text { 1. Results in high total area and greater trabecularization. } \\
\text { 2. Does not lead to altered serum or urine phosphate levels. } \\
\text { 3. Alters body size, food intake and energy expenditure in obese mice. } \\
\text { 4. Increases trabecular bone formation and unusually thin cortical bone } \\
\text { in mice. } \\
\text { 5. Decreases periosteal and endosteal bone formation in mice. }\end{array}$ & $\begin{array}{l}\text { 1. None. } \\
\text { 2. None. } \\
\text { 3. None. } \\
\text { 4. Wnt and BMP signaling. } \\
\text { 5. Repression of the Ror2/Jnk cascade in osteoclasts. }\end{array}$ & $93-96)$ \\
\hline SFRP5 $5^{-/-}$ & $\begin{array}{l}\text { 1. Not essential for axis formation or foregut morphogenesis in the mouse. } \\
\text { 2. Ameliorates mouse liver fibrosis. } \\
\text { 3. Regulates early lympho-hematopoiesis in the maternal bone marrow. } \\
\text { 4. diminishes cardiac inflammation and protects the heart } \\
\text { from ischemia-reperfusion injury }\end{array}$ & $\begin{array}{l}\text { 1. None. } \\
\text { 2. Inhibition of Wnt5a/Fz2 signaling. } \\
\text { 3. Strongly block B-lymphopoiesis. } \\
\text { 4. Block the JNK activation by induction of Wnt5a in bone } \\
\text { marrow derived macrophage }\end{array}$ & $(97-100)$ \\
\hline $\mathrm{SFRP}^{-1 /} / \mathrm{SFRP} 2^{-/-}$ & $\begin{array}{l}\text { 1. Regulates anteroposterior axis elongation and somite segmentation } \\
\text { during mouse embryogenesis } \\
\text { 2. Requires for normal male sexual development. } \\
\text { 3. Regulates retinal neurogenesis. } \\
\text { 4. Requires for maintenance in lens epithelial cells }\end{array}$ & $\begin{array}{l}\text { 1. Alter oscillations of Notch signaling. } \\
\text { 2. Disrupted non-canonical Wnt signaling. } \\
\text { 3. Act as negative modulators of ADAM10. } \\
\text { 4. Wnt/ } \beta \text {-catenin signaling. }\end{array}$ & $(101-104)$ \\
\hline $\begin{array}{l}\mathrm{SFRP}^{-/-} / \mathrm{SFRP} 4^{-/-} \\
\mathrm{SFRP}^{-/ /} / \mathrm{SFRP} 2^{-/-} \\
\text {/SFRP5 }^{-/-}\end{array}$ & $\begin{array}{l}\text { 1. Negatively regulates ovarian follicle development. } \\
\text { 1. Regulates early Trunk Formation in Mouse. }\end{array}$ & $\begin{array}{l}\text { 1. Wnt signaling pathway in ovarian follicle development. } \\
\text { 1. Canonical and non-canonical pathways }\end{array}$ & $\begin{array}{l}(105) \\
(106)\end{array}$ \\
\hline
\end{tabular}

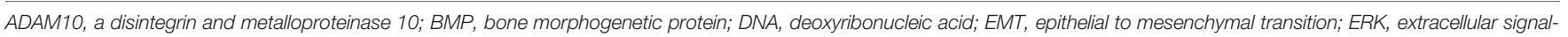

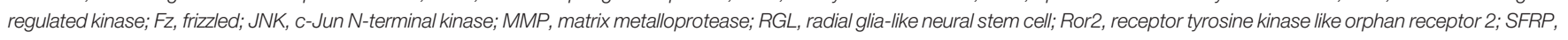
secreted frizzled-related protein; TGF $\beta$, transforming growth factor beta; Wnt, wingless/integrated; Wnt/PCP, Wnt/planar cell polarity.

of circulating SFRP4 which is positively correlated with IR, androgen, ovarian follicle number or ovarian volume (117). Multiples studies aimed to reveal the underlying mechanism of SFRP 4 function. For instance, Mahdi et al. noted that interleukin-1 $\beta$ stimulated SFRP4 secretion impairs glucose tolerance and insulin secretion in islet cells of T2DM patients (36). However, Mastaitis et al. demonstrated that SFRP4 doesn't regulate glucose homeostasis and $\beta$-cell quality in mice, as SFRP4 knockout mice exhibited the same level of impaired glucose tolerance, and the reason was tied to 5 -fold compensation by islet $\beta$ cells (25). microRNAs regulate adipose tissue functions, such as lipolysis, glucose and glycerol conversion and insulin sensitivity (118). The levels of miR-24, miR-30d and miR-146a are higher in abdominal adipose tissue of obese and T2DM patients compared to normal subjects, which positively correlates with the expression of SFRP4 (119). Another group discovered that miR-103a and miR-103b negatively regulate the expression of SFRP4 by regulating the 3'-noncoding region, suggesting that their mutual changes provide high sensitivity and specificity for the identification of patients with pre-diabetes (120).

In a series of clinical cases the analysis of circulating SFRP5 levels in T2DM patients lead to an opposite conclusion. Data showed that circulating SFRP5 level is significantly lower in obese, diabetic and adult latent autoimmune diabetes patients 
compared to normal subjects, and is negatively correlated with BMI, waist circumference, fasting blood glucose, glycosylated hemoglobin, insulin level and IR index, supporting the role of SFRP5 as a protective factor in the pathogenesis of diabetes (121126). To the contrary, Canville et al. reported that the plasma level of SFRP5 was higher in newly diagnosed T2DM patients compared to pre-diabetic or normal subjects, suggesting SFRP5 is an independent risk factor for T2DM (127). The controversial results could be attributed to the following reasons: firstly, medications used in managing diabetes may affect SFRP5 secretion, as Lu et al. reported a clinical analysis including two medications (rosiglitazone and metformin) (122); secondly, the conclusion is based on a small number of cases and the distribution was not equal in T2DM patients and normal control (126); thirdly, age, gender and BMI may affect SFRP5 levels, which were excluded in Canville's study. Central SFRP5 also plays an important role in liver lipid metabolism mainly in reducing food intake, increasing energy consumption, and inhibiting liver glucose flow and very low-density lipoproteintriglyceride production. The mechanism underlying these processes is likely that SFRP5 dependent neural circuit participates in hypothalamic insulin signaling pathway, and inhibits N-methyl-D-aspartate receptor or dorsal vagal complex ATP-sensitive potassium channel mediated hepatic vagus nerve conduction, which then reduces the activities of liver adipogenesis related enzymes and inhibits the secretion of hepatic glucose and very low-density lipoprotein-triglyceride (128). In vitro, glucose inhibits phosphatidylinositol 3-kinase/ Akt pathway and reduces the expression of SFRP5 to slow the proliferation of rat islet $\beta$ cells, indicate that SFRP5 may serve as a target to expand functional pancreatic islets in diabetic patients (129).

\section{THE EFFECT OF SFRPS ON CARDIOVASCULAR DISEASE}

Cardiovascular disease remains a leading cause of mortality worldwide. It is widely accepted that unbalanced cardiovascular remodeling and ischemic injury are the major pathological processes involved in cardiovascular diseases, leading to adverse prognoses. There is therefore a great need for a novel approach to prevent cardiovascular remodeling and ischemic injury. Presently, multiple studies suggest that SFRPs may represent novel therapeutic targets (Figure 4).

\section{Angiogenesis}

Dufourcq et al. demonstrated that SFRP1 inhibits Wnt signaling to increase the angiogenesis of mesenchymal cells, glioma cells and chorioallantoic membrane, making the blood vessels larger, longer and more mature and promoting the migration of endothelial cells (ECs) and the formation of catheters (130). Alternatively, overexpression of SFRP1 inhibits the proliferation of ECs and smooth muscle cells by delaying the G1 to S phase transition, altering the Wnt frizzled pathway and controlling the proliferation and angiogenesis of muscle after ischemia (39).
For these reasons, SFRP1 would be of interest for cardiac surgeons using angiogenic therapy in ischemic heart diseases in non-revascularizable patients. Additionally, SFRP1 interacts with Wnt receptors Fzd4 and Fzd7 to promote ECs' cytoskeletal reorganization and increases neovascularization in ischemiainduced angiogenesis in mouse hindlimbs (131). It is worth mentioning that nuclear factor of activated T cells 3 is required for SFRP2 induced endothelial tube formation (132).

Recent studies indicate that SFRP4 inhibits the formation of pseudopodia and sprouts as well as disrupts the stability of ECs ring via antagonizing the Wnt signaling pathway and inhibiting the nuclear translocation of $\beta$-catenin. This inhibition drives ECs toward apoptosis and inhibits angiogenesis by increasing cellular levels of reactive oxygen species (133). The results of SFRP4 domain analysis revealed that $\mathrm{CRD}$ inhibits the tube formation by ECs, NLD could promote EC death, inhibits angiogenesis and increases intracellular calcium levels in ECs by activating nonclassical $\mathrm{Ca}^{2+}$ Wnt signaling pathway in SFRP4 mediated angiogenesis inhibition, which is suggestive of alternative antiangiogenic downstream targets of canonical Wnt signaling (134).

\section{Myocardial Injury}

SFRP1 regulates myocardial differentiation and the formation of large and small myocardium during embryonic development by inhibiting Wnt6 signaling pathway (135). Besides, SFRP1 protects rat cardiomyoblasts from hypoxia/re-oxygenation injury or transverse aortic constriction induced heart failure by blocking the Wnt signaling pathway $(136,137)$. In addition, overexpression of SFRP1 reduces myocardial rupture, early leukocyte infiltration and apoptosis index as well as increases collagen deposition and capillary density, preferentially improved the myocardial function and infarct size after myocardial infarction (138). In brief, SFRP1 is not only controls the size of the differentiating heart muscle primarily by regulating cell fate within the cardiac mesoderm between muscular and non-muscular cell lineage, but also through direct or indirect interaction with different phases of infarct healing, reduced infarct size and improved cardiac function. Contrary to previous study, during ischemic preconditioning, SFRP1 overexpression reduces GSK-3 $\beta$ phosphorylation levels in the heart. Compared with the littermates, the SFRP1 transgenic mice show larger infarct size and worse cardiac function (139). Conversely, SFRP1 deficiency results in abnormal cardiac structure, dysfunction, ventricular dilatation and hypertrophy, deterioration of cardiac function and a large number of myocardial fibrosis, accompanied with an increase in expression of Wnt ligands (Wnt1, 3, 7b, and 16) and Wnt target genes (Wisp1 and Lef1) in the heart of aged mice (78).

The protective effect of SFRP2 on the heart can be divided into two aspects: one is to promote the proliferation and differentiation of cardiac progenitor cells, the other is functional diversity and signal complexity of SFRP2 in cardiac fibrosis. Typically, overexpression of SFRP2 increases the proliferation rate, reduces apoptosis, inhibits the combination of osteoblasts and chondrocytes and promotes self-renewal ability of MSCs by inhibiting Wnt and bone morphogenetic protein (BMP) signaling pathways to achieve 


\section{SFRPs regulate cardiovascular disease}
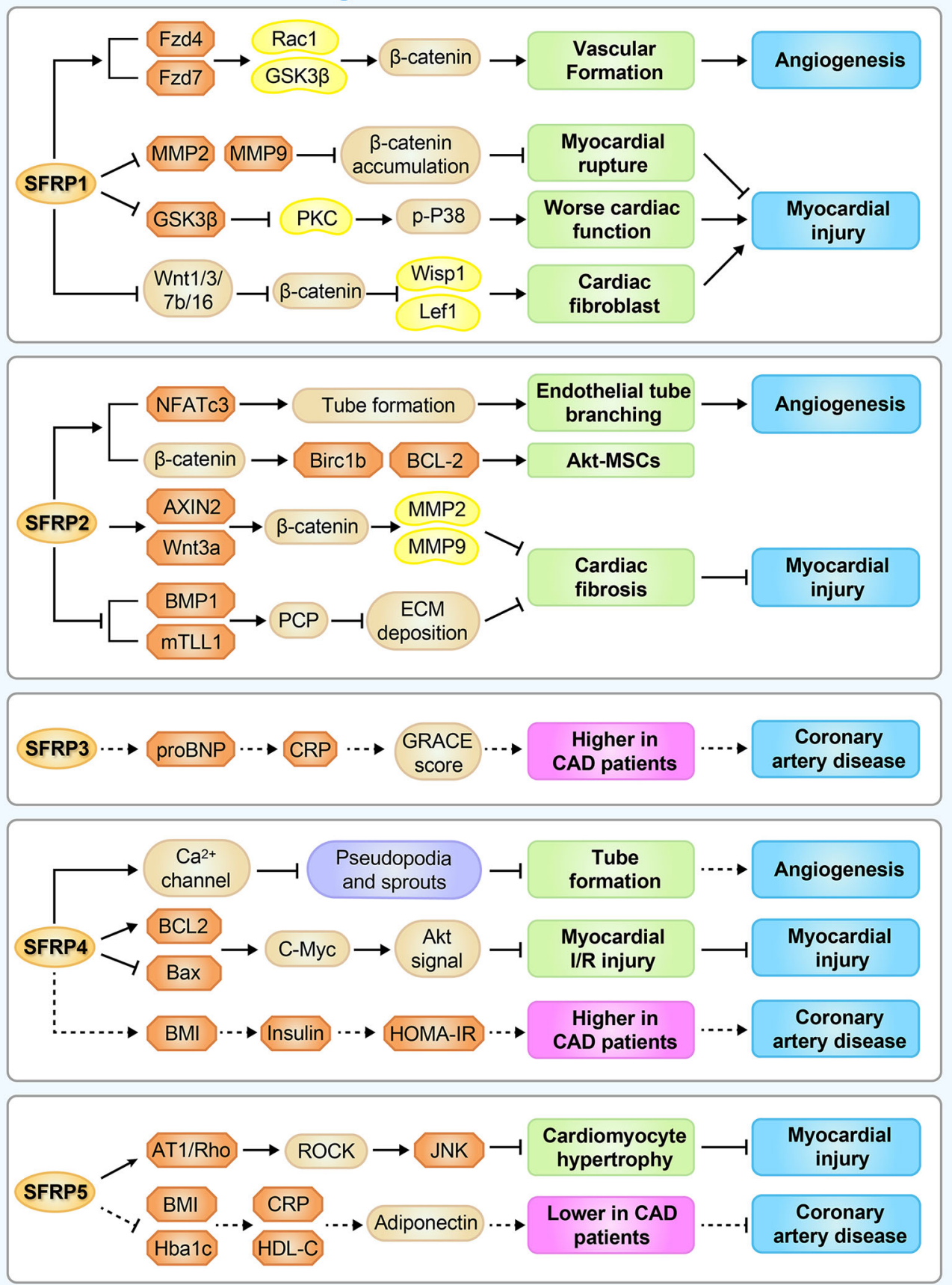

$\longrightarrow$ Up-regulate $\quad \longrightarrow$ Down-regulate $\quad$ Direct effect $\quad \ldots . .$. Indirect effect

FIGURE 4 | A brief overview of the molecular mechanisms by which SFRPs regulate cardiovascular disease. The figure shows the potential mechanisms by which how SFRPs modulate cardiovascular diseases including angiogenesis, myocardial injury and coronary artery disease. AT1, arginine ADP-ribosyltransferase 1; AXIN2, axin protein 2; BAX, BCL2 associated X, apoptosis regulator; BCL-2, B cell leukemia/lymphoma 2; Birc1b, NLR family, apoptosis inhibitory protein 2; BMP1, bone morphogenetic protein 1; C-Myc, MYC proto-oncogene, bHLH transcription factor; CRP, C-reactive protein; ECM deposition, Subclass B3 metallo beta lactamase gene family; Fzd4/7, frizzled class receptor 4/7; HDL-C, High-density lipoprotein; HOMA-IR, Homeostasis model assessment-IR; JNK, C-Jun NH2-terminal kinase; Lef1, lymphoid enhancer binding factor 1; MMP2, matrix metalloproteinase 2; NFATc3, nuclear factor of activated T cells, cytoplasmic, calcineurin dependent 3; PKC, protein kinase C; Rac1, Rac family small GTPase 1; ROCK, Rho-associated coiled-coil containing protein kinase; WISP1, WNT1 inducible signaling pathway protein 1; Wnt1, wingless-type MMTV integration site family, member 1. 
better tissue transplantation and wound healing (140). The ability to regenerate and replace dead myocardium after heart injury is limited, and overexpression of Akt by bone marrow MSCs significantly reduces the infarct size of myocardial injury and restores myocardial function in rodents (141). Overexpression of AKT in MSCs up-regulates SFRP2 by 100 fold to promote myocardial survival and repair after ischemic injury (142). Bone marrow MSCs transplantation is an ideal method to treat ischemic injury, however the insufficient survival rate of transplanted cells in host tissues is a main obstacle halting the progress of cell therapy. Injection of SFRP2-MSCs into the myocardium around myocardial infarction enhances the transplantation, increases the vascular density, decreases the infarct area and enhances the cardiac function after myocardial injury in mice (143). Cardiac progenitor cells are essential for replacement of lost mature cells during injury or turnover (144). Firstly, SFRP2 binds to Wnt6 and inhibits the classic Wnt pathway, slows the proliferation of cardiac progenitor cells and activates Wnt/JNK signaling pathway to induce the differentiation of cardiac progenitor cells (145). Secondly, SFRP2 reduces Wnt3a transcription to prevent mesoderm formation and cardiomyocyte differentiation (146). Collectively, the researchers demonstrate the novel function of SFRP4 in regulating the dynamic process of cardiac progenitor cells proliferation and differentiation, as well as providing new insights into the mechanisms of Wnt signaling in cardiac differentiation. SFRP2 upregulates the expression of Axin2 and Wnt3a to promote the growth of fibroblasts, and increases the expression of matrix metalloproteinase to reduce chronic fibrosis and heart failure after myocardial infarction (147). Antibody blocking SFRP2 activates Axin2 to improve myocardial function and inhibits myocardial fibrosis, which may be a specific target of anti-fibrosis therapy (148). The underlying molecular mechanism by which SFRP2 promotes cardiac fibro-calcification is probably through the coordinate activation of tolloid-like metalloproteinases and TNAP (149). Correspondingly, knockdown of SFRP2 markedly reduces fibrosis in the infracted heart (82). In details, SFRP2 enhances the activity of BMP-1 at low concentrations (10-20 nm), while at high concentration $(100 \mathrm{~nm})$ it specifically inhibits PCP activity, BMP activity and collagen maturation in vitro. In addition, SFRP2 inhibits the maturation of procollagen and increases the accumulation of soluble type I procollagen in a dose-dependent manner, but has no effect on collagen synthesis in total cell lysates (150). In conclusion, SFRP2 inhibits myocardial injury induced fibrosis in a dosedependent manner.

Schumann et al. demonstrated that SFRP3 and SFRP4 are highly expressed in human left ventricle during heart failure, they also enhance the apoptosis susceptibility by antagonizing Wnt signal transduction (151). Moreover, patients with heart failure showed increased levels of circulating SFRP3 which associated with a poor outcome (152). Furthermore, intermediate serum levels of SFRP3 increases survival rate in elderly patients with ischemic chronic heart failure, indicating that balanced Wnt activity may play a protective role in clinical heart failure patients (153). As well known, both transient and permanent ischemic injuries lead to cell death, scar formation and tissue remodeling. Upregulation of SFRP4 in ischemic heart improves cardiac function after permanent and transient ischemic injuries through reduction of cellular scar formation (154). Conversely, SFRP4 knockdown decreases lactate dehydrogenase and creatine kinase levels, increases ventricular function by activating the Akt signaling pathway in the myocardium to alleviate ischemiareperfusion injury by reduce protein expression of Bax, active caspase 3, and increase Bcl-2 and c-Myc in cardiac tissue (155). Altogether, administration of SFRP4 interferes with canonical Wnt signaling that could mediate the formation of acellular scar and consequently contributes to the prevention of aggravation of cardiac function.

The infarct size of SFRP5 knockout mice is significantly larger than wild-type mice. In addition, Wnt5a positive macrophages and inflammatory cytokines increases significantly after ischemia-reperfusion in SFRP5 knockout mice compared to the wild type mice (100). Serum SFRP5 is significantly higher in patients with acute ST segment elevation myocardial infarction (STEMI) compared to patients without CHD, and is negatively correlated with the levels of high-sensitivity cardiac troponin I and C-reactive protein (156). Consequently, angiotensin II increases the expression of SFRP5 in a time and dose-dependent manner, as SFRP5 inhibits the expression of natriuretic peptide $b$ and tumor necrosis factor alpha in hypertrophic cardiomyocytes through AT1 receptor/Rho/ Rock1/JNK signaling pathway, which plays an important role in the pathological process of cardiac hypertrophy (157). Otherwise, the ancestral heart is accompanied by the generation and remake of progenitor cells after the acquisition of pulmonary circulation. The expression of SFRP5 begins at the lateral side of the crescent and continues to be expressed at the venous pole, indicating that the outflow tract, left ventricle, atrium and venous sinus originates from the common progenitor cells, while the right ventricle is not (158).

\section{Coronary Artery Disease}

Wnt signaling is involved in atherosclerotic plaque formation directly and indirectly by modulating cardiovascular risk factors. Baseline systemic SFRP1 levels are significantly higher in patients with cardiovascular events compared to healthy controls (159). SFRP3 is a predictor of all-cause mortality and re-hospitalization due to stroke in a large population of acute coronary syndrome patients with long-term follow-up. The association between adverse events and intermediate SFRP3 levels is further supported when combining intermediate SFRP3 levels and advanced GRACE score, further supports a role for the Wnt pathways in the progression of clinical atherosclerosis involving the regulation of soluble Wnt modulators (160).

SFRP4 mRNA and protein expression are significantly higher in $\mathrm{CAD}$ patients compared to non-CAD in epicardial adipose tissue (EAT) and plasma. Moreover, EAT SFRP4 mRNA levels and plasma SFRP4 concentrations are independently associated with the presence of CAD by multivariate linear regression analysis (161). Additionally, the levels of SFRP4 in control group are significantly lower than those in T2DM, CHD and $\mathrm{T} 2 \mathrm{D}+\mathrm{CHD}$, indicating that SFRP4 may be a predictive marker for atherosclerosis particularly in diabetic patients (162). 
Additional report indicates that the serum level of SFRP5 is significantly lower in patients with $\mathrm{CAD}$ compared to patients without $\mathrm{CAD}$, and is negatively correlated with the severity of CAD (163). In order to further clarify the relationship between SFRP5 and cardiovascular disease risk factors, a large populationbased cohort study was conducted and demonstrated that the increase of serum SFRP5 is negatively correlated with various risk factors of T2DM and cardiovascular disease, indicating that SFRP5, as a new biomarker, needs further investigation as a mediator in the prevention of cardiac metabolic diseases (24, 164). The ratio of SFRP5 to Wnt5a is lower in EAT and serum in CAD patients compared to healthy subjects. Besides, the serum level of SFRP5 is also lower in CAD patients compared to the healthy subjects and negatively associates with the presence of CAD. SFRP5 is secreted by visceral fat and its local concentration in EAT may greatly exceed that in subcutaneous adipose, indicating that low SFRP5 and high Wnt5a levels are associated with the presence of $\mathrm{CAD}$, independent of other conventional risk factors (165). Adiposity, the level of c-reactive protein, leptin and $\mathrm{C}-\mathrm{C}$ motif chemokine ligand 2 are higher in Mexican Americans consuming a diet high in sugar sweetened beverages, however, the expression of SFRP5 is lower in participants with diet rich in fruits, vegetables and includes low sugar sweetened beverages intake, this reveals that diet contributes to adiposity and proinflammation (166).

\section{CONCLUSION AND PERSPECTIVE}

Over the past 30 years, SFRPs family members have become a popular research topic. The expanding family of SFRPs, with their multiple functions, provides abundant research targets and contributes to the development of novel therapies. In this review, we summarize the influence of SFRPs protein on physiological and pathological processes related to lipid metabolism and cardiovascular protection (Figures 3, 4). Although many important scientific problems have been solved since SFRPs proteins were first described, there are still many problems to be solved. (1) In the study of adipogenesis in mice, what makes SFRPs specific in regulating adipogenesis and what is the mechanism leading to this difference? (2) In clinical research, the physiological levels of SFRPs proteins changed greatly (Tables 2, 3). It is necessary to further clarify whether the SFRPs levels are regulated during the development of obesity and diabetes mellitus since there is still controversy on whether the SFRPs levels are higher or lower than a specific threshold to affect metabolism. (3) In the development of cardiovascular disease, the expression levels of SFRPs protein are changed. In the future, whether SFRPs can be used as markers for the diagnosis or prediction of cardiovascular diseases, such as CHD, atherosclerosis, etc. (4) Identifying SFRPs receptors is still a major challenge and there is a need to provide in-depth

TABLE 2 | The clinic study about the concentration of SFRPs in patients with metabolism disease.

\begin{tabular}{|c|c|c|c|}
\hline Genotype & Study population (number) & Concentration of SFRPs & Reference \\
\hline SFRP4 & $\begin{array}{l}\text { Obese Patients Study } \\
\text { Lean }(n=8) ; \text { obese }(n=12) \text {. }\end{array}$ & Obese: $137.8 \pm 33.6 \mathrm{ng} / \mathrm{mL}$; Lean: $64.1 \pm 23.8 \mathrm{ng} / \mathrm{mL}$. & $(61)$ \\
\hline SFRP4 & $\begin{array}{l}\text { Obese Patients Study } \\
\text { LF }(n=21) ; \operatorname{LGl}(n=21) ; \operatorname{VLC}(n=21)\end{array}$ & PW: $1086 \pm 167$ pg/mL; LF: $1307 \pm 181 \mathrm{pg} / \mathrm{mL} ;$ LGl: $1346 \pm 211$ pg/mL; VLC: $1220 \pm 205$ pg/mL. & $(60)$ \\
\hline SFRP4 & $\begin{array}{l}\text { Diabetic Study } \\
\text { NGT }(n=42) ; \text { IGT( } n=52) ; \text { T2DM }(n=56) \text {. }\end{array}$ & NGT: $95.46 \pm 20.13$ ng/mL; IGT: $141.64 \pm 40.46$ ng/mL; T2DM: $184.38 \pm 61.34$ ng/mL. & (113) \\
\hline SFRP4 & $\begin{array}{l}\text { Diabetic Study } \\
\text { Control }(n=30) ; \text { T1D }(n=46) ; \text { T2D }(n=55) \text {; } \\
\text { CO-T1D }(n=30) ; \text { LADA }(n=37)\end{array}$ & $\begin{array}{l}\text { Control: } 8.8 \pm 3.0 \mathrm{ng} / \mathrm{mL} ; \mathrm{CO}-\mathrm{T} 1 \mathrm{D}: 16.9 \pm 4.5 \mathrm{ng} / \mathrm{mL} ; \mathrm{T} 2 \mathrm{D}: 37.1 \pm 26.7 \mathrm{ng} / \mathrm{mL} ; \text { LADA: } 15.6 \pm 6.2 \\
\mathrm{ng} / \mathrm{mL} ; \text { T1D: } 24.6 \pm 17.9 \mathrm{ng} / \mathrm{mL} .\end{array}$ & $(114)$ \\
\hline SFRP4 & $\begin{array}{l}\text { Diabetic Study } \\
\text { NGT ( } n=36) ; \text { IGT }(n=34) ; \text { T2DM ( } n=82) \text {. }\end{array}$ & NGT: 0.170 (0.12-0.45) ng/mL; IGT: $0.183(0.13-0.70)$ ng/mL; T2DM: $0.282(0.11-2.51)$ ng/mL. & $(115)$ \\
\hline SFRP4 & $\begin{array}{l}\text { Pregnant with Diabetic Study } \\
\text { Control }(n=41) ; \text { GDM }(n=35)\end{array}$ & Control: $5.59 \pm 3.32 \mathrm{ng} / \mathrm{mL} ;$ GDM: $4.05 \pm 2.15 \mathrm{ng} / \mathrm{mL}$ & $(116)$ \\
\hline SFRP4 & $\begin{array}{l}\text { Women with PCOS } \\
\text { Control }(n=80) ; \text { PCOS }(n=80) \text {. }\end{array}$ & Control: $5.87 \pm 1.91 \mathrm{ng} / \mathrm{mL}$; PCOS: $3.72 \pm 1.29 \mathrm{ng} / \mathrm{mL}$ & $(117)$ \\
\hline SFRP5 & $\begin{array}{l}\text { Diabetic Study } \\
\text { NGT-NW }(n=46) ; \text { NGT-OB }(n=43) ; \\
\text { T2DM-NW }(n=42) ; \text { T2DM-OB }(n=45) \text {. }\end{array}$ & $\begin{array}{l}\text { NGT-NW :13.12 } \pm 3.62 \text { ng/mL; NGT-OB: } 9.46 \pm 2.70 \text { ng/mL; T2DM-NW: } 10.12 \pm 3.45 \mathrm{ng} / \mathrm{mL} \text {; } \\
\text { T2DM-OB: } 6.70 \pm 2.34 \text { ng/mL; Men: } 9.71 \pm 3.86 \text { ng/mL; Women: } 10.01 \pm 3.82 \text { ng/mL. }\end{array}$ & $(121)$ \\
\hline SFRP5 & $\begin{array}{l}\text { Diabetic Study } \\
\text { T2DM ( } n=82) \text {, non-diabetics }(n=42)\end{array}$ & 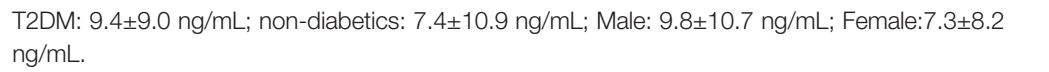 & $(122)$ \\
\hline SFRP5 & $\begin{array}{l}\text { Diabetic Study } \\
\text { Controls ( } n=40) ; \text { T2DM }(n=58) ; \text { LADA } \\
(n=22) \text {. }\end{array}$ & Controls: $22.98 \pm 12.36$ ng/mL; T2DM: $14.14 \pm 11.91 \mathrm{ng} / \mathrm{mL} ;$ LADA: $14.82 \pm 11.27 \mathrm{ng} / \mathrm{mL}$. & $(124)$ \\
\hline SFPR5 & $\begin{array}{l}\text { MetS Study } \\
\text { Control ( } n=194) ; \text { MetS patients }(n=90) \text {. }\end{array}$ & Control subjects: $61.6 \pm 23.2 \mu \mathrm{g} / \mathrm{L}$; MetS patients: $49.1 \pm 17.2 \mu \mathrm{g} / \mathrm{L}$. & (125) \\
\hline SFRP5 & $\begin{array}{l}\text { Diabetic Study } \\
\text { Controls }(n=70) ; \text { T2DM }(n=70) ; \\
\text { prediabetic subjects }(n=70)\end{array}$ & Controls: 10.4 (6.7-16.6) ng/mL; T2DM: 15.6 (9-24.5) ng/mL; prediabetic subjects: 9.8(5-14.2) ng/mL. & $(127)$ \\
\hline
\end{tabular}

CO-T1D, controls, age matched for patients with type 1 diabetes; GDM, gestational diabetes mellitus; IGT, impaired glucose tolerance; LADA, latent autoimmune diabetes of the adult; LF, Iow fat; LGI, low glycemic index; MetS, metabolic syndrome; NGT, normal glucose tolerance; NGT-NW, normal glucose tolerance-Normal weight; NGT-OB, normal glucose toleranceobese; PCOS, polycystic ovary syndrome; PW, pre-weight; T1D, type 1 diabetes; T2, type 2 diabetes; T2DM, type 2 diabetes mellitus; T2DM-NW, type 2 diabetes mellitus-normal weight; T2DM-OB, type 2 diabetes mellitus-obese; VLC, very low carbohydrate. 
TABLE 3 | The clinic study about the concentration of SFRPs in patients with cardiovascular disease.

\begin{tabular}{|c|c|c|c|}
\hline Genotype & Study population & Concentration of SFRPs & References \\
\hline SFRP1 & $\begin{array}{l}\text { Cardiovascular disease: Controls }(n=157) \text {; Patients } \\
\text { with cardiovascular events }(n=) \text {. }\end{array}$ & Control: 2609.0 [1926.1-3234.9] pg/mL; CVD: 3221.8 [2352.8-3811.0] pg/mL. & $(159)$ \\
\hline SFRP3 & HF study: Controls ( $n=25)$; HF patients ( $n=153)$. & Control:1.83 (1.40, 2.46) ng/mL; HF patients: 2.83 (2.46, 3.62) ng/mL. & $(167)$ \\
\hline SFRP4 & Cardiovascular disease: CAD patients $(n=504)$. & Control: 12.21 (3.64 - 41.2) $\mu \mathrm{g} / \mathrm{L} ;$ CAD patients: $11.21(9.17,13.86) \mu \mathrm{g} / \mathrm{L}$. & $(10)$ \\
\hline SFRP4 & Cardiovascular disease: Non-CAD $(n=30) ;$ CAD $(n=30)$. & non-CAD: $14.5 \pm 2.3 \mathrm{ng} / \mathrm{mL}$. CAD: $16.8 \pm 3.3 \mathrm{ng} / \mathrm{mL}$ & $(161)$ \\
\hline SFRP4 & $\begin{array}{l}\text { Cardiovascular disease: Control }(n=35) ; D M(n=37) \\
\text { CAD }(n=34) ; \text { CAD+DM }(n=36)\end{array}$ & $\begin{array}{l}\text { Control:1.41 (1.24-1.67) ng/mL; DM: } 1.70 \text { (1.51-2.45) ng/mL; CAD: } 1.58 \text { (1.31- } \\
\text { 2.55) ng/mL; CAD+DM: } 2.02 \text { (1.47-3.47) ng/mL. }\end{array}$ & $(162)$ \\
\hline SFRP5 & $\begin{array}{l}\text { Cardiovascular disease: non-CAD }(n=57) ; C A D \\
(n=128) \text {. }\end{array}$ & non-CAD: 52.4 [29.6] ng/mL; CAD: 47.7 [26.6] ng/mL; & $(163)$ \\
\hline SFRP5 & Cardiovascular disease: non-CAD ( $n=29)$; CAD $(n=58)$. & non-CAD: $21.27 \pm 3.38$ ng/mL; CAD: $16.23 \pm 3.17$ ng/mL. & $(165)$ \\
\hline SFRP5 & Ml study: no-CAD ( $n=35) ;$ STEMI $(n=85)$. & no-CAD: 19.8 ng/mL; STEMl: 23.3 ng/mL. & $(156)$ \\
\hline
\end{tabular}

CAD, Cardiovascular disease; DM, Diabetes mellitus; HF, Heart failure; MI, Myocardial infarction; SFRP, Secreted frizzled-related protein; STEMI, ST-Elevation Myocardial Infarction.

insights into the signaling pathways controlled by each of the SFRPs and the unique biological functions they mediate.

We conclude that our current knowledge about the role of SFRPs family proteins in IR, $\beta$ cell dysfunction, type 2 diabetes and the natural cause of cardiovascular disease is still limited. The same is true of their potential relevance in regulating disease progression to improve metabolic process. However, we look forward to more basic and clinical research on SFRPs in the future, which can be used as a bedding for clinical treatment. Although previous studies have shown that SFRPs family proteins have the potential to be used as biomarkers, so far, the relevant research conclusions are not enough to support their use as molecular markers to predict diseases. Due to the contradictory conclusions of several similar studies $(25,36,38$, $65)$, more basic and clinical studies are still needed in the future, and more theoretical basis is needed to prove its feasibility as a molecular marker.

\section{AUTHOR CONTRIBUTIONS}

HG, LX and XG conceived this manuscript. HG, JZ and ZH collected and prepared the related references. HG, JZ and JL drafted the manuscript. HG, HX and $\mathrm{ZH}$ drew the figures. HX

\section{REFERENCES}

1. Bluher M. Obesity: Global Epidemiology and Pathogenesis. Nat Rev Endocrinol (2019) 15:288-98. doi: 10.1038/s41574-019-0176-8

2. Dewidar B, Kahl S, Pafili K, Roden M. Metabolic Liver Disease in Diabetes From Mechanisms to Clinical Trials. Metabolism (2020) 111S:154299. doi: 10.1016/j.metabol.2020.154299

3. Kassi E, Pervanidou P, Kaltsas G, Chrousos G. Metabolic Syndrome: Definitions and Controversies. BMC Med (2011) 9:48. doi: 10.1186/17417015-9-48

4. Rattner A, Hsieh J-C, Smallwood PM, Gilbert DJ, Copeland NG, Jenkins NA, et al. A Family of Secreted Proteins Contains Homology to the Cysteine-Rich Ligand-Binding Domain of Frizzled Receptors. Proc Natl Acad Sci USA (1997) 94:2859-63. doi: 10.1073/pnas.94.7.2859

5. Taciak B, Pruszynska I, Kiraga L, Bialasek M, Krol M. Wnt Signaling Pathway in Development and Cancer. J Physiol Pharmacol (2018) 69:185196. doi: 10.26402/jpp.2018.2.07

6. Manandhar S, Kabekkodu SP, Pai KSR. Aberrant Canonical Wnt Signaling: Phytochemical Based Modulation. Phytomedicine (2020) 76:153243. doi: 10.1016/j.phymed.2020.153243 and QY performed data analysis and tabulation. LX, and XG and QY supervised and revised the manuscript. $\mathrm{HG}$ and $\mathrm{ZH}$ summarized the contents of the article and drew the graphical abstracts. All authors contributed to the article and approved the submitted version.

\section{FUNDING}

This work was supported by grants from National Natural Science Foundation of China (grant: 81900399), Natural Science Foundation Project of Shaanxi Province (grants: 2020JZ-56, 2021JQ-785, 19JS060, 2016JM8122, 2020JM-605) and State Administration of Traditional Chinese Medicine of Shaanxi Province (grant: 2019-ZZ-JC034), the Key Research and Development Plan of Shaanxi Province (grant: 2018SF-266), Xi'an Medical University Scientific Research Fund (grant: 2018DOC12, 2016RCYJ01).

\section{ACKNOWLEDGMENTS}

We express ours' sincere thanks to RL, YW, ML and RX for their assistance and warmly help.

7. Nusse R, Clevers H. Wnt/beta-Catenin Signaling, Disease, and Emerging Therapeutic Modalities. Cell (2017) 169:985-99. doi: 10.1016/ j.cell.2017.05.016

8. Agostino M, Pohl SO. Wnt Binding Affinity Prediction for Putative FrizzledType Cysteine-Rich Domains. Int J Mol Sci (2019) 20:4168. doi: 10.3390/ ijms 20174168

9. Lagathu C, Christodoulides C, Tan CY, Virtue S, Laudes M, Campbell M, et al. Secreted Frizzled-Related Protein 1 Regulates Adipose Tissue Expansion and Is Dysregulated in Severe Obesity. Int J Obes (2010) 34:1695-705. doi: 10.1038/ijo.2010.107

10. Hoffmann MM, Werner C, Böhm M, Laufs U, Winkler K. Association of Secreted Frizzled-Related Protein 4 (Sfrp4) With Type 2 Diabetes in Patients With Stable Coronary Artery Disease. Cardiovasc Diabetol (2014) 13:155. doi: 10.1186/s12933-014-0155-2

11. Huang AQ, Huang YL. Role of Sfrps in Cardiovascular Disease. Ther Adv Chronic Dis (2020) 11:2040622320901990. doi: 10.1177/20406223 20901990

12. Jones SE, Jomary C. Secreted Frizzled-Related Proteins: Searching for Relationships and Patterns. BioEssays: News Rev Mol Cell Dev Biol (2002) 24:811-20. doi: 10.1002/bies.10136 
13. Bhat RA, Stauffer B, Komm BS, Bodine PV. Structure-Function Analysis of Secreted Frizzled-Related Protein-1 for Its Wnt Antagonist Function. J Cell Biochem (2007) 102:1519-28. doi: 10.1002/jcb.21372

14. Bányai L, Patthy L. The Ntr Module: Domains of Netrins, Secreted Frizzled Related Proteins, and Type I Procollagen C-Proteinase Enhancer Protein Are Homologous With Tissue Inhibitors of Metalloproteases. Protein Sci (1999) 8:1636-42. doi: 10.1110/ps.8.8.1636

15. Chuman Y, Üren A, Cahill J, Regan C, Wolf V, Kay BK, et al. Identification of a Peptide Binding Motif for Secreted Frizzled-Related Protein-1. Peptides (2004) 25:1831-8. doi: 10.1016/j.peptides.2004.07.010

16. Bukhari S, Shamshari W, Ur-Rahman M, Zia-Ul-Haq M, Jaafar H. Computer Aided Screening of Secreted Frizzled-Related Protein 4 (Sfrp4): A Potential Control for Diabetes Mellitus. Molecules (2014) 19:10129-36. doi: 10.3390/molecules190710129

17. Yam JWP, Chan KW, Ngan ESW, Hsiao WLW. Genomic Structure, Alternative Splicing and Tissue Expression of Rfrp/Sfrp-4, the Rat Frizzled Related Protein Gene. Gene (2005) 357:55-62. doi: 10.1016/j.gene.2005.05.025

18. Van Camp JK, Beckers S, Zegers D, Verhulst SL, Van Hoorenbeeck K, Massa G, et al. Nucleotide Variation of Sfrp5 Gene Is Not Associated With Obesity in Children and Adolescents. Mol Biol Rep (2016) 43:1041-7. doi: 10.1007/ s11033-016-4050-7

19. Tendeng C, Houart C. Cloning and Embryonic Expression of Five Distinct Sfrp Genes in the Zebrafish Danio Rerio. Gene Expression Patterns: GEP (2006) 6:761-71. doi: 10.1016/j.modgep.2006.01.006

20. Cruciat CM, Niehrs C. Secreted and Transmembrane Wnt Inhibitors and Activators. Cold Spring Harbor Perspect Biol (2012) 5:a015081. doi: 10.1101/ cshperspect.a015081

21. Zhong X, Desilva T, Lin L, Bodine P, Bhat RA, Presman E, et al. Regulation of Secreted Frizzled-Related Protein-1 by Heparin. J Biol Chem (2007) 282:20523-33. doi: 10.1074/jbc.M609096200

22. Wang Y, Mashock M, Tong Z, Mu XF, Chen H, Zhou X, et al. Changing Technologies of Rna Sequencing and Their Applications in Clinical Oncology. Front Oncol (2020) 10:447. doi: 10.3389/fonc.2020.00447

23. Bennett CN, Ross SE, Longo KA, Bajnok L, Hemati N, Johnson KW, et al. Regulation of Wnt Signaling During Adipogenesis. J Biol Chem (2002) 277:30998-1004. doi: 10.1074/jbc.M204527200

24. Fagerberg L, Hallstrom BM, Oksvold P, Kampf C, Djureinovic D, Odeberg J, et al. Analysis of the Human Tissue-Specific Expression by Genome-Wide Integration of Transcriptomics and Antibody-Based Proteomics. Mol Cell Proteomics: MCP (2014) 13:397-406. doi: 10.1074/mcp.M113.035600

25. Mastaitis J, Eckersdorff M, Min S, Xin Y, Cavino K, Aglione J, et al. Loss of Sfrp4 Alters Body Size, Food Intake, and Energy Expenditure in DietInduced Obese Male Mice. Endocrinology (2015) 156:4502-10. doi: 10.1210/en.2015-1257

26. Heller RS, Dichmann DS, Jensen J, Miller C, Wong G, Madsen OD, et al. Expression Patterns of Wnts, Frizzleds, Sfrps, and Misexpression in Transgenic Mice Suggesting a Role for Wnts in Pancreas and Foregut Pattern Formation. Dev Dynamics (2002) 225:260-70. doi: 10.1002/dvdy.10157

27. Routledge D, Scholpp S. Mechanisms of Intercellular Wnt Transport. Development (2019) 146:dev176073. doi: 10.1242/dev.176073

28. Galli LM, Barnes T, Cheng T, Acosta L, Anglade A, Willert K, et al. Differential Inhibition of Wnt-3a by Sfrp-1, Sfrp-2, and Sfrp-3. Dev Dynamics (2006) 235:681-90. doi: 10.1002/dvdy.20681

29. von Marschall Z, Fisher LW. Secreted Frizzled-Related Protein-2 (Sfrp2) Augments Canonical Wnt3a-Induced Signaling. Biochem Biophys Res Commun (2010) 400:299-304. doi: 10.1016/j.bbrc.2010.08.043

30. Xavier CP, Melikova M, Chuman Y, Üren A, Baljinnyam B, Rubin J, et al. AndSecreted Frizzled-Related Protein Potentiation Versus Inhibition of Wnt3a/ $\beta$-Catenin Signaling. Cell Signalling (2014) 26:94-101. doi: 10.1016/j.cellsig.2013.09.016

31. Chena M-H, Antonib L, Tazi-Ahninib R, Corkb M, Wardb SJ, Ba ${ }^{\circ}$ vik CO. Identification of Known and Novel Genes Whose Expression Is Regulated by Endogenous Retinoic Acid During Early Embryonic Development of the Mouse. Mech Dev (2002) 114:205-12. doi: 10.1016/S0925-4773(02)00066-7

32. Katoh M, Katoh M. Wnt Signaling Pathway and Stem Cell Signaling Network. Clin Cancer Res (2007) 13:4042-5. doi: 10.1158/1078-0432.CCR06-2316
33. Zeng G, Awan F, Otruba W, Muller P, Apte U, Tan X, et al. Wnt'er in Liver: Expression of Wnt and Frizzled Genes in Mouse. Hepatology (2007) 45:195204. doi: 10.1002/hep.21473

34. Park JR, Jung JW, Lee YS, Kang KS. The Roles of Wnt Antagonists Dkk1 and Sfrp4 During Adipogenesis of Human Adipose Tissue-Derived Mesenchymal Stem Cells. Cell Proliferation (2008) 41:859-74. doi: 10.1111/j.1365-2184.2008.00565.x

35. De A. Wnt/ca2+ Signaling Pathway: A Brief Overview. Acta Biochim Biophys $\operatorname{Sin}$ (2011) 43:745-56. doi: 10.1093/abbs/gmr079

36. Mahdi T, Hanzelmann S, Salehi A, Muhammed SJ, Reinbothe TM, Tang Y, et al. Secreted Frizzled-Related Protein 4 Reduces Insulin Secretion and Is Overexpressed in Type 2 Diabetes. Cell Metab (2012) 16:625-33. doi: 10.1016/j.cmet.2012.10.009

37. Humphries AC, Mlodzik M. From Instruction to Output: Wnt/pcp Signaling in Development and Cancer. Curr Opin Cell Biol (2018) 51:110-6. doi: 10.1016/j.ceb.2017.12.005

38. Ouchi N, Higuchi A, Ohashi K, Oshima Y, Gokce N, Shibata R, et al. Sfrp5 Is an Anti-Inflammatory Adipokine That Modulates Metabolic Dysfunction in Obesity. Science (2010) 329:454-7. doi: 10.1126/science.1188280

39. Poulos SP, Dodson MV, Culver MF, Hausman GJ. The Increasingly Complex Regulation of Adipocyte Differentiation. Exp Biol Med (2016) 241:449-56. doi: 10.1177/1535370215619041

40. Song TX, Kuang SH. Adipocyte Dedifferentiation in Health and Diseases. Clin Sci (Lond) (2019) 133:2107-19. doi: 10.1042/CS20190128

41. Ehrlund A, Mejhert N, Lorente-Cebrián S, Åström G, Dahlman I, Laurencikiene J, et al. Characterization of the Wnt Inhibitors Secreted Frizzled-Related Proteins (Sfrps) in Human Adipose Tissue. J Clin Endocrinol Metab (2013) 98:E503-8. doi: 10.1210/jc.2012-3416

42. Bahmad HF, Daouk R, Azar J, Sapudom J, Teo JCM, Abou-Kheir W, et al. Modeling Adipogenesis: Current and Future Perspective. Cells (2020) 9:2326. doi: 10.3390/cells9102326

43. Gauger KJ, Bassa LM, Henchey EM, Wyman J, Bentley B, Brown M, et al. Mice Deficient in Sfrp1 Exhibit Increased Adiposity, Dysregulated Glucose Metabolism, and Enhanced Macrophage Infiltration. PloS One (2013) 8: e78320. doi: 10.1371/journal.pone.0078320

44. Kumar S, Leontovich A, Coenen MJ, Bahn RS. Gene Expression Profiling of Orbital Adipose Tissue From Patients With Graves' Ophthalmopathy: A Potential Role for Secreted Frizzled-Related Protein-1 in Orbital Adipogenesis. J Clin Endocrinol Metab (2005) 90:4730-5. doi: 10.1210/ jc.2004-2239

45. Lagathu C, Christodoulides C, Virtue S, Cawthorn WP, Franzin C, Kimber WA, et al. Dact1, a Nutritionally Regulated Preadipocyte Gene, Controls Adipogenesis by Coordinating the Wnt/-Catenin Signaling Network. Diabetes (2008) 58:609-19. doi: 10.2337/db08-1180

46. Wang L, Wang Y, Meng Y, Zhang C, Di L. Gsk3-Activated Stat5 Regulates Expression of Sfrps to Modulate Adipogenesis. FASEB J (2018) 32:4714-26. doi: 10.1096/fi.201701314R

47. Wang LY, Shan TZ. Factors Inducing Transdifferentiation of Myoblasts Into Adipocytes. J Cell Physiol (2020) 236(4):2276-89. doi: 10.1002/jcp.30074

48. Abdallah BM, Kassem M. New Factors Controlling the Balance Between Osteoblastogenesis and Adipogenesis. Bone (2012) 50:540-5. doi: 10.1016/ j.bone.2011.06.030

49. Taipaleenmäki H, Abdallah BM, AlDahmash A, Säämänen A-M, Kassem M. Wnt Signalling Mediates the Cross-Talk Between Bone Marrow Derived Pre-Adipocytic and Pre-Osteoblastic Cell Populations. Exp Cell Res (2011) 317:745-56. doi: 10.1016/j.yexcr.2010.12.015

50. Akimoto T, Ushida T, Miyaki S, Akaogi H, Tsuchiya K, Yan Z, et al. Mechanical Stretch Inhibits Myoblast-to-Adipocyte Differentiation Through Wnt Signaling. Biochem Biophys Res Commun (2005) 329:381-5. doi: 10.1016/j.bbrc.2005.01.136

51. Guan H, Zhang Y, Gao S, Bai L, Zhao S, Cheng XW, et al. Differential Patterns of Secreted Frizzled-Related Protein 4 (Sfrp4) in Adipocyte Differentiation: Adipose Depot Specificity. Cell Physiol Biochem (2018) 46:2149-64. doi: 10.1159/000489545

52. Visweswaran M, Schiefer L, Arfuso F, Dilley RJ, Newsholme P, Dharmarajan A. Wnt Antagonist Secreted Frizzled-Related Protein 4 Upregulates Adipogenic Differentiation in Human Adipose Tissue-Derived 
Mesenchymal Stem Cells. PloS One (2015) 10:e0118005. doi: 10.1371/ journal.pone. 0118005

53. Qi Q, Wang Y, Wang X, Yang J, Xie Y, Zhou J, et al. Histone Demethylase Kdm4a Regulates Adipogenic and Osteogenic Differentiation via Epigenetic Regulation of C/Ebpalpha and Canonical Wnt Signaling. Cell Mol Life Sci: CMLS (2019) 77(12):2407-21. doi: 10.1007/s00018-019-03289-w

54. Lv C, Jiang Y, Wang H, Chen B. Sfrp5 Expression and Secretion in Adipocytes Are Up-Regulated During Differentiation and Are Negatively Correlated With Insulin Resistance. Cell Biol Int (2012) 36:851-5. doi: 10.1042/CBI20120054

55. Zoico E, Darra E, Rizzatti V, Budui S, Franceschetti G, Mazzali G, et al. Adipocytes Wnt5a Mediated Dedifferentiation: A Possible Target in Pancreatic Cancer Microenvironment. Oncotarget (2016) 7:20223-35. doi: 10.18632/oncotarget.7936

56. Zeng J, Hu J, Lian Y, Jiang Y, Chen B. Sfrp5 Is a Target Gene Transcriptionally Regulated by Ppary in 3t3-L1 Adipocytes. Gene (2017) 641:190-5. doi: 10.1016/j.gene.2017.10.066

57. Wang R, Hong J, Liu R, Chen M, Xu M, Gu W, et al. Sfrp5 Acts as a Mature Adipocyte Marker But Not as a Regulator in Adipogenesis. Soc Endocrinol (2014) 53:405-15. doi: 10.1530/JME-14-0037

58. Crowley RK, O’Reilly MW, Bujalska IJ, Hassan-Smith ZK, Hazlehurst JM, Foucault DR, et al. Sfrp2 Is Associated With Increased Adiposity and Vegf Expression. PloS One (2016) 11:e0163777. doi: 10.1371/journal.pone.0163777

59. Schübel R, Sookthai D, Greimel J, Johnson T, Grafetstätter M, Kirsten R, et al. Key Genes of Lipid Metabolism and Wnt-Signaling Are Downregulated in Subcutaneous Adipose Tissue With Moderate Weight Loss. Nutrients (2019) 11:639. doi: 10.3390/nu11030639

60. Hron BM, Ebbeling CB, Feldman HA, Ludwig DS. Hepatic, Adipocyte, Enteric and Pancreatic Hormones: Response to Dietary Macronutrient Composition and Relationship With Metabolism. Nutr Metab (2017) 14:44. doi: 10.1186/s12986-017-0198-y

61. Garufi G, Seyhan AA, Pasarica M. Elevated Secreted Frizzled-Related Protein 4 in Obesity: A Potential Role in Adipose Tissue Dysfunction. Obesity (2015) 23:24-7. doi: 10.1002/oby.20915

62. Hörbelt T, Knebel B, Fahlbusch P, Barbosa D, de Wiza DH, Van de Velde F, et al. The Adipokine Sfrp4 Induces Insulin Resistance and Lipogenesis in the Liver. Biochim Biophys Acta (BBA) Mol Basis Dis (2019) 1865:2671-84. doi: 10.1016/j.bbadis.2019.07.008

63. Herder C, Carstensen M, Ouwens DM. Anti-Inflammatory Cytokines and Risk of Type 2 Diabetes. Diabetes Obes Metab (2013) Suppl 3:39-50. doi: 10.1111/dom.12155

64. Rulifson IC, Majeti JZ, Xiong Y, Hamburger A, Jeong K, Lee, et al. Inhibition of Secreted Frizzled-Related Protein 5 Improves Glucose Metabolism. Am J Physiol Endocrinol Metab (2014) 307:E1144-52. doi: 10.1152/ajpendo. 00283.2014

65. Mori H, Prestwich TC, Reid MA, Longo KA, Gerin I, Cawthorn WP, et al. Secreted Frizzled-Related Protein 5 Suppresses Adipocyte Mitochondrial Metabolism Through Wnt Inhibition. J Clin Invest (2012) 122:2405-16. doi: 10.1172/JCI63604

66. Rauch A, Mandrup S. Lighting the Fat Furnace Without Sfrp5. J Clin Invest (2012) 122:2349-52. doi: 10.1172/JCI64196

67. Catalán V, Gómez-Ambrosi J, Rodríguez A, Pérez-Hernández AI, Gurbindo J, Ramírez B, et al. Activation of Noncanonical Wnt Signaling Through Wnt5a in Visceral Adipose Tissue of Obese Subjects Is Related to Inflammation. J Clin Endocrinol Metab (2014) 99:E1407-17. doi: 10.1210/ jc.2014-1191

68. Bodine PV, Zhao W, Kharode YP, Bex FJ, Lambert AJ, Goad MB, et al. The Wnt Antagonist Secreted Frizzled-Related Protein-1 Is a Negative Regulator of Trabecular Bone Formation in Adult Mice. Mol Endocrinol (2004) 18:1222-37. doi: 10.1210/me.2003-0498

69. Esteve P, Crespo I, Kaimakis P, Sandonis A, Bovolenta P. Sfrp1 Modulates Cell-Signaling Events Underlying Telencephalic Patterning, Growth and Differentiation. Cereb Cortex (2019) 29:1059-74. doi: 10.1093/cercor/bhy013

70. Foronjy R, Imai K, Shiomi T, Mercer B, Sklepkiewicz P, Thankachen J, et al. The Divergent Roles of Secreted Frizzled Related Protein-1 (Sfrp1) in Lung Morphogenesis and Emphysema. Am J Pathol (2010) 177:598-607. doi: 10.2353/ajpath.2010.090803
71. Gauger KJ, Bassa LM, Henchey EM, Wyman J, Ser-Dolansky J, Shimono A, et al. The Effects of Diet Induced Obesity on Breast Cancer Associated Pathways in Mice Deficient in Sfrp1. Mol Cancer (2014) 13:117. doi: 10.1186/1476-4598-13-117

72. Gauger KJ, Schneider SS. Tumour Supressor Secreted Frizzled Related Protein 1 Regulates P53-Mediated Apoptosis. Cell Biol Int (2014) 38:12430. doi: $10.1002 /$ cbin. 10176

73. Gauger KJ, Shimono A, Crisi GM, Schneider SS. Loss of Sfrp1 Promotes Ductal Branching in the Murine Mammary Gland. BMC Dev Biol (2012) 12:25. doi: 10.1186/1471-213X-12-25

74. Gaur T, Wixted JJ, Hussain S, O'Connell SL, Morgan EF, Ayers DC, et al. Secreted Frizzled Related Protein 1 Is a Target to Improve Fracture Healing. J Cell Physiol (2009) 220:174-81. doi: 10.1002/jcp.21747

75. Gregory KJ, Morin SM, Schneider SS. Regulation of Early Growth Response 2 Expression by Secreted Frizzled Related Protein 1. BMC Cancer (2017) 17:473. doi: 10.1186/s12885-017-3426-y

76. Matsuyama M, Nomori A, Nakakuni K, Shimono A, Fukushima M. Secreted Frizzled-Related Protein 1 (Sfrp1) Regulates the Progression of Renal Fibrosis in a Mouse Model of Obstructive Nephropathy. J Biol Chem (2014) 289:31526-33. doi: 10.1074/jbc.M114.584565

77. Renstrom J, Istvanffy R, Gauthier K, Shimono A, Mages J, Jardon-Alvarez A, et al. Secreted Frizzled-Related Protein 1 Extrinsically Regulates Cycling Activity and Maintenance of Hematopoietic Stem Cells. Cell Stem Cell (2009) 5:157-67. doi: 10.1016/j.stem.2009.05.020

78. Sklepkiewicz P, Shiomi T, Kaur R, Sun J, Kwon S, Mercer B, et al. Loss of Secreted Frizzled-Related Protein-1 Leads to Deterioration of Cardiac Function in Mice and Plays a Role in Human Cardiomyopathy. Circ Heart Fail (2015) 8:362-72. doi: 10.1161/CIRCHEARTFAILURE.114.001274

79. Sunkara RR, Sarate RM, Setia P, Shah S, Gupta S, Chaturvedi P, et al. Sfrp1 in Skin Tumor Initiation and Cancer Stem Cell Regulation With Potential Implications in Epithelial Cancers. Stem Cell Rep (2020) 14:271-84. doi: 10.1016/j.stemcr.2019.12.006

80. Trevant B, Gaur T, Hussain S, Symons J, Komm BS, Bodine P, et al. Expression of Secreted Frizzled Related Protein 1, A Wnt Antagonist, in Brain, Kidney, and Skeleton Is Dispensable for Normal Embryonic Development. J Cell Physiol (2008) 217(1):113-26. doi: 10.1002/jcp.21482

81. Berthon A, Drelon C, Ragazzon B, Boulkroun S, Tissier F, Amar L, et al. Wnt/beta-Catenin Signalling Is Activated in Aldosterone-Producing Adenomas and Controls Aldosterone Production. Hum Mol Genet (2014) 23:889-905. doi: $10.1093 / \mathrm{hmg} / \mathrm{ddt} 484$

82. Kobayashi K, Luo M, Zhang Y, Wilkes DC, Ge G, Grieskamp T, et al. Secreted Frizzled-Related Protein 2 Is a Procollagen C Proteinase Enhancer With a Role in Fibrosis Associated With Myocardial Infarction. Nat Cell Biol (2009) 11:46-55. doi: 10.1038/ncb1811

83. Morello R, Bertin TK, Schlaubitz S, Shaw CA, Kakuru S, Munivez E, et al. Brachy-Syndactyly Caused by Loss of Sfrp2 Function. J Cell Physiol (2008) 217:127-37. doi: $10.1002 /$ jcp. 21483

84. Skah S, Nadjar J, Sirakov M, Plateroti M. The Secreted Frizzled-Related Protein 2 Modulates Cell Fate and the Wnt Pathway in the Murine Intestinal Epithelium. Exp Cell Res (2015) 330:56-65. doi: 10.1016/ j.yexcr.2014.10.014

85. Bernascone I, Gonzalez T, Barea MD, Carabana C, Hachimi M, BoschFortea M, et al. Sfrp3 Modulates Stromal-Epithelial Crosstalk During Mammary Gland Development by Regulating Wnt Levels. Nat Commun (2019) 10:2481. doi: 10.1038/s41467-019-10509-1

86. Casas-Fraile L, Cornelis FM, Costamagna D, Rico A, Duelen R, Sampaolesi MM, et al. Frizzled Related Protein Deficiency Impairs Muscle Strength, Gait and Calpain 3 Levels. Orphanet J Rare Dis (2020) 15:119. doi: 10.1186/ s13023-020-01372-1

87. Jang MH, Kitabatake Y, Kang E, Jun H, Pletnikov MV, Christian KM, et al. Secreted Frizzled-Related Protein 3 (Sfrp3) Regulates Antidepressant Responses in Mice and Humans. Mol Psychiatry (2013) 18:957-8. doi: 10.1038/mp.2012.158

88. Lodewyckx L, Cailotto F, Thysen S, Luyten FP, Lories RJ. Tight Regulation of Wingless-Type Signaling in the Articular Cartilage - Subchondral Bone Biomechanical Unit: Transcriptomics in Frzb-Knockout Mice. Arthritis Res Ther (2012) 14:R16. doi: 10.1186/ar3695 
89. Lories RJ, Peeters J, Bakker A, Tylzanowski P, Derese I, Schrooten J, et al. Articular Cartilage and Biomechanical Properties of the Long Bones in FrzbKnockout Mice. Arthritis Rheum (2007) 56:4095-103. doi: 10.1002/art.23137

90. Lories RJ, Peeters J, Szlufcik K, Hespel P, Luyten FP. Deletion of FrizzledRelated Protein Reduces Voluntary Running Exercise Performance in Mice. Osteoarthritis Cartilage (2009) 17:390-6. doi: 10.1016/j.joca.2008.07.018

91. Sun J, Bonaguidi MA, Jun H, Guo JU, Sun GJ, Will B, et al. A SeptoTemporal Molecular Gradient of Sfrp3 in the Dentate Gyrus Differentially Regulates Quiescent Adult Hippocampal Neural Stem Cell Activation. Mol Brain (2015) 8:52. doi: 10.1186/s13041-015-0143-9

92. Thysen S, Cailotto F, Lories R. Osteogenesis Induced by Frizzled-Related Protein (Frzb) Is Linked to the Netrin-Like Domain. Lab Invest (2016) 96:570-80. doi: 10.1038/labinvest.2016.38

93. Brommage R, Jeter-Jones S, Xiong W, Liu J. Microct Analyses of Mouse Femoral Neck Architecture. Bone (2019) 145:115040. doi: 10.1016/ j.bone.2019.115040

94. Christov M, Koren S, Yuan Q, Baron R, Lanske B. Genetic Ablation of Sfrp4 in Mice Does Not Affect Serum Phosphate Homeostasis. Endocrinology (2011) 152:2031-6. doi: 10.1210/en.2010-1351

95. Kiper POS, Saito H, Gori F, Unger S, Hesse E, Yamana K, et al. Cortical-Bone Fragility-Insights From Sfrp4 Deficiency in Pyle's Disease. N Engl J Med (2016) 374:2553-62. doi: 10.1056/NEJMoa1509342

96. Chen K, Ng PY, Chen R, Hu D, Berry S, Baron R, et al. Sfrp4 Repression of the Ror2/Jnk Cascade in Osteoclasts Protects Cortical Bone From Excessive Endosteal Resorption. Proc Natl Acad Sci USA (2019) 116:14138-43. doi: 10.1073/pnas. 1900881116

97. Leaf I, Tennessen J, Mukhopadhyay M, Westphal H, Shawlot W. Sfrp5 Is Not Essential for Axis Formation in the Mouse. Genesis (2006) 44:573-8. doi: $10.1002 /$ dvg. 20248

98. Chatani N, Kamada Y, Kizu T, Ogura S, Furuta K, Egawa M, et al. Secreted Frizzled-Related Protein 5 (Sfrp5) Decreases Hepatic Stellate Cell Activation and Liver Fibrosis. Liver Int (2015) 35:2017-26. doi: 10.1111/liv.12757

99. Yokota T, Oritani K, Sudo T, Ishibashi T, Doi Y, Habuchi Y, et al. EstrogenInducible Sfrp5 Inhibits Early B-Lymphopoiesis In Vivo, But Not During Pregnancy. Eur J Immunol (2015) 45:1390-401. doi: 10.1002/eji.201444939

100. Nakamura K, Sano S, Fuster JJ, Kikuchi R, Shimizu I, Ohshima K, et al. Secreted Frizzled-Related Protein 5 Diminishes Cardiac Inflammation and Protects the Heart From Ischemia/Reperfusion Injury. J Biol Chem (2016) 291:2566-75. doi: 10.1074/jbc.M115.693937

101. Satoh W, Gotoh T, Tsunematsu Y, Aizawa S, Shimono A. Sfrp1 and Sfrp2 Regulate Anteroposterior Axis Elongation and Somite Segmentation During Mouse Embryogenesis. Development (2006) 133:989-99. doi: 10.1242/ dev.02274

102. Warr N, Siggers P, Bogani D, Brixey R, Pastorelli L, Yates L, et al. Sfrp1 and Sfrp2 Are Required for Normal Male Sexual Development in Mice. Dev Biol (2009) 326:273-84. doi: 10.1016/j.ydbio.2008.11.023

103. Esteve P, Sandonis A, Cardozo M, Malapeira J, Ibanez C, Crespo I, et al. Sfrps Act as Negative Modulators of Adam10 to Regulate Retinal Neurogenesis. Nat Neurosci (2011) 14:562-9. doi: 10.1038/nn.2794

104. Sugiyama Y, Shelley EJ, Wen L, Stump RJ, Shimono A, Lovicu FJ, et al. Sfrp1 and Sfrp2 Are Not Involved in Wnt/Beta-Catenin Signal Silencing During Lens Induction But Are Required for Maintenance of Wnt/Beta-Catenin Signaling in Lens Epithelial Cells. Dev Biol (2013) 384:181-93. doi: 10.1016/ j.ydbio.2013.10.008

105. Zamberlam G, Lapointe E, Abedini A, Rico C, Godin P, Paquet M, et al. Sfrp4 Is a Negative Regulator of Ovarian Follicle Development and Female Fertility. Endocrinology (2019) 160:1561-72. doi: 10.1210/en.2019-00212

106. Satoh W, Matsuyama M, Takemura H, Aizawa S, Shimono A. Sfrp1, Sfrp2, and Sfrp5 Regulate the Wnt/Beta-Catenin and the Planar Cell Polarity Pathways During Early Trunk Formation in Mouse. Genesis (2008) 46:92103. doi: $10.1002 /$ dvg. 20369

107. Anunciado-Koza R, Higgins DC, Koza RA. Adipose Tissue Mest and Sfrp5 Are Concomitant With Variations of Adiposity Among Inbred Mouse Strains Fed a Non-Obesogenic Diet. Biochimie (2015) 124:134-40. doi: 10.1016/j.biochi.2015.05.007

108. Akoumianakis I, Sanna F, Margaritis M, Badi I, Akawi N, Herdman L, et al. Adipose Tissue-Derived Wnt5a Regulates Vascular Redox Signaling in
Obesity via Usp17/Rac1-Mediated Activation of Nadph Oxidases. Sci Transl Med (2019) 11:eaav5055. doi: 10.1126/scitranslmed.aav5055

109. Gonzalez LL, Garrie K, Turner MD. Type 2 Diabetes - an Autoinflammatory Disease Driven by Metabolic Stress. Biochimica Et Biophysica Acta. Mol Basis Dis (2018) 1864:3805-23. doi: 10.1016/j.bbadis.2018.08.034

110. Schinner S, Ülgen F, Papewalis C, Schott M, Woelk A, Vidal-Puig A, et al. Regulation of Insulin Secretion, Glucokinase Gene Transcription and Beta Cell Proliferation by Adipocyte-Derived Wnt Signalling Molecules. Diabetologia (2007) 51:147-54. doi: 10.1007/s00125-007-0848-0

111. Pachori AS, Madan M, Nunez Lopez YO, Yi F, Meyer C, Seyhan A, et al. Reduced Skeletal Muscle Secreted Frizzled-Related Protein 3 Is Associated With Inflammation and Insulin Resistance. Obesity (2017) 25:697-703. doi: $10.1002 /$ oby.21787

112. Bergmann K, Sypniewska G. Secreted Frizzled-Related Protein 4 (Sfrp4) and Fractalkine (Cx3cl1) - Potential New Biomarkers for $\beta$-Cell Dysfunction and Diabetes. Clin Biochem (2014) 47:529-32. doi: 10.1016/j. clinbiochem.2014.03.007

113. Liu F, Qu H, Li Y, Tang Q, Yang Z, Wang H, et al. Relationship Between Serum Secreted Frizzled-Related Protein 4 Levels and the First-Phase of Glucose-Stimulated Insulin Secretion in Individuals With Different Glucose Tolerance. Endocr J (2015) 62:733-40. doi: 10.1507/endocrj.EJ15-0212

114. Brix JM, Krzizek EC, Hoebaus C, Ludvik B, Schernthaner G, Schernthaner GH. Secreted Frizzled-Related Protein 4 (Sfrp4) Is Elevated in Patients With Diabetes Mellitus. Hormone Metab Res Hormon Und Stoffwechselforschung Hormones Metabol (2016) 48:345-8. doi: 10.1055/s-0041-111698

115. Baldane S, Ipekci SH, Ekin A, Abusoglu S, Unlu A, Kebapcilar L. Evaluation of Fractalkine (Fkn) and Secreted Frizzled-Related Protein 4 (Sfrp-4) Serum Levels in Patients With Prediabetes and Type 2 Diabetes. Bratislavske Lekarske Listy (2018) 119:112-5. doi: 10.4149/BLL_2018_021

116. Baldane S, Ipekci SH, Kebapcilar AG, Abusoglu A, Beyhekim H, Ilhan TT, et al. Prorenin and Secreted Frizzled-Related Protein 4 Levels in Women With Gestational Diabetes Mellitus. Bratislavske Lekarske Listy (2018) 119:450-3. doi: 10.4149/BLL_2018_083

117. Bicer M, Alarslan P, Guler A, Demir I, Aslanipour B, Calan M. Elevated Circulating Levels of Secreted Frizzled-Related Protein 4 in Relation to Insulin Resistance and Androgens in Women With Polycystic Ovary Syndrome. J Endocrinol Invest (2019) 43:305-13. doi: 10.1007/s40618-01901108-4

118. Schulte DM, Müller N, Neumann K, Oberhäuser F, Faust M, Güdelhöfer H, et al. Pro-Inflammatory Wnt5a and Anti-Inflammatory Sfrp5 Are Differentially Regulated by Nutritional Factors in Obese Human Subjects. PloS One (2012) 7:e32437. doi: 10.1371/journal.pone.0032437

119. Nunez Lopez YO, Garufi G, Pasarica M, Seyhan AA. Elevated and Correlated Expressions of Mir-24, Mir-30d, Mir-146a, and Sfrp-4 in Human Abdominal Adipose Tissue Play a Role in Adiposity and Insulin Resistance. Int J Endocrinol (2018) 2018:1-7. doi: 10.1155/2018/7351902

120. Luo M, Xu C, Luo Y, Wang G, Wu J, Wan Q. Circulating Mir-103 Family as Potential Biomarkers for Type 2 Diabetes Through Targeting Cav-1 and Sfrp4. Acta Diabetol (2019) 57:309-22. doi: 10.1007/s00592-019-01430-6

121. Hu Z, Deng H, Qu H. Plasma Sfrp5 Levels Are Decreased in Chinese Subjects With Obesity and Type 2 Diabetes and Negatively Correlated With Parameters of Insulin Resistance. Diabetes Res Clin Pract (2013) 99:391-5. doi: 10.1016/j.diabres.2012.11.026

122. Lu YC, Wang CP, Hsu CC, Chiu CA, Yu TH, Hung WC, et al. Circulating Secreted Frizzled-Related Protein 5 and Wingless-Type Mmtv Integration Site Family Member 5 a Levels in Patients With Type 2 Diabetes Mellitus. Diabetes/Metabol Res Rev (2013) 29(7):551-6. doi: 10.1002/dmrr.2426

123. Toan NL, Van Hoan N, Cuong DV, Dung NV, Dung PT, Hang NT, et al. Adipose Tissue-Derived Cytokines and Their Correlations With Clinical Characteristics in Vietnamese Patients With Type 2 Diabetes Mellitus. Diabetol Metab Syndrome (2018) 10:41. doi: 10.1186/s13098-018-0343-4

124. Cheng L, Zhang D, Chen B. Declined Plasma Sfrp5 Concentration in Patients With Type 2 Diabetes and Latent Autoimmune Diabetes in Adults. Pak J Med Sci (2015) 31:602-5. doi: 10.12669/pjms.313.6964

125. Xu Q, Wang H, Li Y, Wang J, Lai Y, Gao L, et al. Plasma Sfrp5 Levels Correlate With Determinants of the Metabolic Syndrome in Chinese Adults. Diabetes/Metabol Res Rev (2017) 33. doi: 10.1002/dmrr.2896 
126. Carstensen-Kirberg M, Hatziagelaki E, Tsiavou A, Chounta A, Nowotny P, Pacini G, et al. Sfrp5 Associates With Beta-Cell Function in Humans. Eur J Clin Invest (2016) 46:535-43. doi: 10.1111/eci.12629

127. Canivell S, Rebuffat S, Ruano EG, Kostov B, Siso-Almirall A, Novials A, et al. Circulating Sfrp5 Levels Are Elevated in Drug-Naive Recently Diagnosed Type 2 Diabetic Patients as Compared With Prediabetic Subjects and Controls. Diabetes/Metabol Res Rev (2015) 31:212-9. doi: 10.1002/dmrr.2599

128. Li Y, Tian M, Yang M, Yang G, Chen J, Wang H, et al. Central Sfrp5 Regulates Hepatic Glucose Flux and Vldl-Triglyceride Secretion. Metabol: Clin $\operatorname{Exp}$ (2020) 103:154029. doi: 10.1016/j.metabol.2019.154029

129. Guan B, Li W, Li F, Xie Y, Ni Q, Gu Y, et al. Sfrp5 Mediates Glucose-Induced Proliferation in Rat Pancreatic $\beta$-Cells. J Endocrinol (2016) 229:73-83. doi: 10.1530/JOE-15-0535

130. Gregoire FM, Smas CM, Sul HS. Understanding Adipocyte Differentiation. Physiol Rev (1998) 78:783-809. doi: 10.1152/physrev.1998.78.3.783

131. Dufourcq P, Leroux L, Ezan J, Descamps B, Lamaziere JM, Costet P, et al. Regulation of Endothelial Cell Cytoskeletal Reorganization by a Secreted Frizzled-Related Protein-1 and Frizzled 4- and Frizzled 7-Dependent Pathway: Role in Neovessel Formation. Am J Pathol (2008) 172:37-49. doi: 10.2353/ajpath.2008.070130

132. Siamakpour-Reihani S, Caster J, Bandhu Nepal D, Courtwright A, Hilliard E, Usary J, et al. The Role of Calcineurin/Nfat in Sfrp2 Induced Angiogenesis-a Rationale for Breast Cancer Treatment With the Calcineurin Inhibitor Tacrolimus. PloS One (2011) 6:e20412. doi: 10.1371/journal.pone. 0020412

133. Muley A, Majumder S, Kolluru GK, Parkinson S, Viola H, Hool L, et al. Secreted Frizzled-Related Protein 4-An Angiogenesis Inhibitor. Am J Pathol (2010) 176:1505-16. doi: 10.2353/ajpath.2010.090465

134. Longman D, Arfuso F, Viola HM, Hool LC, Dharmarajan AM. The Role of the Cysteine-Rich Domain and Netrin-Like Domain of Secreted Frizzled-Related Protein 4 in Angiogenesis Inhibition In Vitro. Oncol Res (2012) 20:1-6. doi: 10.3727/096504012x13425470196010

135. Gibb N, Lavery DL, Hoppler S. Sfrp1 Promotes Cardiomyocyte Differentiation in Xenopus via Negative-Feedback Regulation of Wnt Signalling. Development (2013) 140:1537-49. doi: 10.1242/dev.088047

136. Pan S, Zhao X, Wang X, Tian X, Wang Y, Fan R, et al. Sfrp1 Attenuates TacInduced Cardiac Dysfunction by Inhibiting Wnt Signaling PathwayMediated Myocardial Apoptosis in Mice. Lipids Health Dis (2018) 17:202. doi: 10.1186/s12944-018-0832-3

137. Tao J, Abudoukelimu M, Ma YT, Yang YN, Li XM, Chen BD, et al. Secreted Frizzled Related Protein 1 Protects H9c2 Cells From Hypoxia/ReOxygenation Injury by Blocking the Wnt Signaling Pathway. Lipids Health Dis (2016) 15:72. doi: 10.1186/s12944-016-0240-5

138. Barandon L, Couffinhal T, Ezan J, Dufourcq P, Costet P, Alzieu P, et al. Reduction of Infarct Size and Prevention of Cardiac Rupture in Transgenic Mice Overexpressing Frza. Circulation (2003) 108:2282-9. doi: 10.1161/01. CIR.0000093186.22847.4C

139. Barandon L, Dufourcq P, Costet P, Moreau C, Allieres C, Daret D, et al. Involvement of Frza/Sfrp-1 and the Wnt/Frizzled Pathway in Ischemic Preconditioning. Circ Res (2005) 96:1299-306. doi: 10.1161/01. RES.0000171895.06914.2c

140. Alfaro MP, Vincent A, Saraswati S, Thorne CA, Hong CC, Lee E, et al. Sfrp2 Suppression of Bone Morphogenic Protein (BMP) and Wnt Signaling Mediates Mesenchymal Stem Cell (Msc) Self-Renewal Promoting Engraftment and Myocardial Repair. J Biol Chem (2010) 285:35645-53. doi: 10.1074/jbc.M110.135335

141. Ozhan G, Weidinger G. Wnt/beta-Catenin Signaling in Heart Regeneration. Cell Regeneration (2015) 4:3. doi: 10.1186/s13619-015-0017-8

142. Mirotsou M, Zhang Z, Deb A, Zhang L, Gnecchi M, Noiseux N, et al. Secreted Frizzled Related Protein 2 (Sfrp2) Is the Key Akt-Mesenchymal Stem Cell-Released Paracrine Factor Mediating Myocardial Survival and Repair. Proc Natl Acad Sci (2007) 104:1643-8. doi: 10.1073/pnas. 0610024104

143. Alfaro MP, Pagni M, Vincent A, Atkinson J, Hill MF, Cates J, et al. The Wnt Modulator Sfrp2 Enhances Mesenchymal Stem Cell Engraftment, Granulation Tissue Formation and Myocardial Repair. Proc Natl Acad Sci USA (2008) 105:18366-71. doi: 10.1073/pnas.0803437105
144. Urbanek K, Cesselli D, Rota M, Nascimbene A, De Angelis A, Hosoda T, et al. Stem Cell Niches in the Adult Mouse Heart. Proc Natl Acad Sci USA (2006) 103:9226-31. doi: 10.1073/pnas.0600635103

145. Hunter CS, Stein RW. Evidence for Loss in Identity, De-Differentiation, and Trans-Differentiation of Islet Beta-Cells in Type 2 Diabetes. Front Genet (2017) 8:35. doi: 10.3389/fgene.2017.00035

146. Deb A, Davis BH, Guo J, Ni A, Huang J, Zhang Z, et al. Sfrp2 Regulates Cardiomyogenic Differentiation by Inhibiting a Positive Transcriptional Autofeedback Loop of Wnt3a. Stem Cells (2008) 26:35-44. doi: 10.1634/ stemcells.2007-0475

147. Lin H, Angeli M, Chung KJ, Ejimadu C, Rosa AR, Lee T. Sfrp2 Activates Wnt/B-Catenin Signaling in Cardiac Fibroblasts: Differential Roles in Cell Growth, Energy Metabolism, and Extracellular Matrix Remodeling. Am J Physiol Cell Physiol (2016) 11:C710-9. doi: 10.1152/ajpcell.00137.2016

148. Mastri M, Shah Z, Hsieh K, Wang X, Wooldridge B, Martin S, et al. Secreted Frizzled-Related Protein 2 as a Target in Antifibrotic Therapeutic Intervention. Am J Physiol Cell Physiol (2014) 306:C531-9. doi: 10.1152/ ajpcell.00238.2013

149. Martin S, Lin H, Ejimadu C, Lee T. Tissue-Nonspecific Alkaline Phosphatase as a Target of Sfrp2 in Cardiac Fibroblasts. Am J Physiol Cell Physiol (2015) 309:C139-47. doi: 10.1152/ajpcell.00009.2015

150. He W, Zhang L, Ni A, Zhang Z, Mirotsou M, Mao L, et al. Exogenously Administered Secreted Frizzled Related Protein 2 (Sfrp2) Reduces Fibrosis and Improves Cardiac Function in a Rat Model of Myocardial Infarction. Proc Natl Acad Sci USA (2010) 107:21110-5. doi: 10.1073/pnas.1004708107

151. Schumann H, Holtz J, Zerkowski HR, Hatzfeld M. Expression of Secreted Frizzled Related Proteins 3 and 4 in Human Ventricular Myocardium Correlates With Apoptosis Related Gene Expression. Cardiovasc Res (2000) 45:720-8. doi: 10.1016/S0008-6363(99)00376-4

152. Askevold ET, Aukrust P, Nymo SH, Lunde IG, Kaasbøll OJ, Aakhus S, et al. The Cardiokine Secreted Frizzled-Related Protein 3, a Modulator of Wnt Signalling, in Clinical and Experimental Heart Failure. Assoc Publ J Internal Med (2013) 275:621-30. doi: 10.1111/joim.12175

153. Askevold ET, Gullestad L, Nymo S, Kjekshus J, Yndestad A, Latini R, et al. Secreted Frizzled Related Protein 3 in Chronic Heart Failure: Analysis From the Controlled Rosuvastatin Multinational Trial in Heart Failure (Corona). PloS One (2015) 10:e0133970. doi: 10.1371/journal.pone.0133970

154. Matsushima K, Suyama T, Takenaka C, Nishishita N, Ikeda K, Ikada Y, et al. Secreted Frizzled Related Protein 4 Reduces Fibrosis Scar Size and Ameliorates Cardiac Function After Ischemic Injury. Tissue Eng Part A (2010) 16:3329-41. doi: 10.1089/ten.tea.2009.0739

155. Zeng W, Cao Y, Jiang W, Kang G, Huang J, Xie S. Knockdown of Sfrp4 Attenuates Apoptosis to Protect Against Myocardial Ischemia/Reperfusion Injury. J Pharmacol Sci (2019) 140:14-9. doi: 10.1016/j.jphs.2019.04.003

156. Du Y, Zhao Y, Zhu Y, Hu C, Zhang J, Ji Q, et al. High Serum Secreted Frizzled-Related Protein 5 Levels Associates With Early Improvement of Cardiac Function Following St-Segment Elevation Myocardial Infarction Treated by Primary Percutaneous Coronary Intervention. J Atheroscl Thromb (2019) 26:868-78. doi: 10.5551/jat.47019

157. Jin X, Guo B, Yan J, Yang R, Chang L, Wang Y, et al. Angiotensin Ii Increases Secreted Frizzled-Related Protein 5 (Sfrp5) Expression Through At1 Receptor/Rho/Rock1/Jnk Signaling in Cardiomyocytes. Mol Cell Biochem (2015) 408:215-22. doi: 10.1007/s11010-015-2497-9

158. Fujii M, Sakaguchi A, Kamata R, Nagao M, Kikuchi Y, Evans SM, et al. Sfrp5 Identifies Murine Cardiac Progenitors for All Myocardial Structures Except for the Right Ventricle. Nat Commun (2017) 8:14664. doi: 10.1038/ ncomms 14664

159. Ress C, Paulweber M, Goebel G, Willeit K, Rufinatscha K, Strobl A, et al. Circulating Wnt Inhibitory Factor 1 Levels Are Associated With Development of Cardiovascular Disease. Atherosclerosis (2018) 273:1-7. doi: 10.1016/j.atherosclerosis.2018.03.045

160. Ueland T, Caidahl K, Askevold ET, Karlsson T, Hartford M, Aukrust P. Secreted Frizzled-Related Protein 3 (Sfrp3) in Acute Coronary Syndromes. Int J Cardiol (2015) 190:217-9. doi: 10.1016/j.ijcard.2015.03.401

161. Ji Q, Zhang J, Du Y, Zhu E, Wang Z, Que B, et al. Human Epicardial Adipose Tissue-Derived And Circulating Secreted Frizzled-Related Protein 4 (Sfrp4) Levels Are Increased In Patients With Coronary Artery Disease. Cardiovasc Diabetol (2017) 16:133. doi: 10.1186/s12933-017-0612-9 
162. Senyigit A, Uzun H, Gultepe I, Konukoglu D. The Relationship Between Carotid Intima-Media Thickness and Serum Secreted Frizzled-Related Protein-4 and Dipeptidyl Peptidase-4 in Diabetic Patients With Cardiovascular Diseases. Bratislava Med J (2019) 120:188-94. doi: 10.4149/BLL_2019_032

163. Miyoshi T, Doi M, Usui S, Iwamoto M, Kajiya M, Takeda K, et al. Low Serum Level of Secreted Frizzled-Related Protein 5, an Anti-Inflammatory Adipokine, Is Associated With Coronary Artery Disease. Atherosclerosis (2014) 233:454-9. doi: 10.1016/j.atherosclerosis.2014.01.019

164. Arner P, Kulyte A. Microrna Regulatory Networks in Human Adipose Tissue and Obesity. Nat Rev Endocrinol (2015) 11:276-88. doi: 10.1038/ nrendo.2015.25

165. Tong S, Du Y, Ji Q, Dong R, Cao J, Wang Z, et al. Expression of Sfrp5/Wnt5a in Human Epicardial Adipose Tissue and Their Relationship With Coronary Artery Disease. Life Sci (2020) 245:117338. doi: 10.1016/j.lfs.2020.117338

166. Koebnick C, Black MH, Wu J, Shu Y-H, MacKay AW, Watanabe RM, et al. A Diet High in Sugar-Sweetened Beverage and Low in Fruits and Vegetables Is Associated With Adiposity and a Pro-Inflammatory Adipokine Profile. $\mathrm{Br} \mathrm{J}$ Nutr (2018) 120:1230-9. doi: 10.1017/S0007114518002726

167. Askevold ET, Aukrust P, Nymo SH, Lunde IG, Kaasbøll OJ, Aakhus S, et al. The Cardiokine Secreted Frizzled-Related Protein 3, A Modulator of Wnt
Signalling, in Clinical and Experimental Heart Failure. J Intern Med (2014) 275:621-30. doi: 10.1111/joim.12175

Conflict of Interest: The authors declare that the research was conducted in the absence of any commercial or financial relationships that could be construed as a potential conflict of interest.

Publisher's Note: All claims expressed in this article are solely those of the authors and do not necessarily represent those of their affiliated organizations, or those of the publisher, the editors and the reviewers. Any product that may be evaluated in this article, or claim that may be made by its manufacturer, is not guaranteed or endorsed by the publisher.

Copyright (C) 2021 Guan, Zhang, Luan, Xu, Huang, Yu, Gou and Xu. This is an openaccess article distributed under the terms of the Creative Commons Attribution License (CC BY). The use, distribution or reproduction in other forums is permitted, provided the original author(s) and the copyright owner(s) are credited and that the original publication in this journal is cited, in accordance with accepted academic practice. No use, distribution or reproduction is permitted which does not comply with these terms. 